\title{
Generation of pluripotent stem cells without the use of genetic material
}

\author{
Akon Higuchi 1,2,9, Qing-Dong Ling ${ }^{3,4,9}$, S Suresh Kumar ${ }^{5}$, Murugan A Munusamy², Abdullah A Alarfaj², \\ Yung Chang ${ }^{6}$, Shih-Hsuan Kao ${ }^{1}$, Ke-Chen Lin ${ }^{1}$, Han-Chow Wang ${ }^{7}$ and Akihiro Umezawa ${ }^{8}$
}

Induced pluripotent stem cells (iPSCs) provide a platform to obtain patient-specific cells for use as a cell source in regenerative medicine. Although iPSCs do not have the ethical concerns of embryonic stem cells, iPSCs have not been widely used in clinical applications, as they are generated by gene transduction. Recently, iPSCs have been generated without the use of genetic material. For example, protein-induced PSCs and chemically induced PSCs have been generated by the use of small and large (protein) molecules. Several epigenetic characteristics are important for cell differentiation; therefore, several small-molecule inhibitors of epigenetic-modifying enzymes, such as DNA methyltransferases, histone deacetylases, histone methyltransferases, and histone demethylases, are potential candidates for the reprogramming of somatic cells into iPSCs. In this review, we discuss what types of small chemical or large (protein) molecules could be used to replace the viral transduction of genes and/or genetic reprogramming to obtain human iPSCs.

Laboratory Investigation (2015) 95, 26-42; doi:10.1038/labinvest.2014.132; published online 3 November 2014

Pluripotent stem cells (PSCs) can be derived from terminally differentiated tissues by altering the epigenetic status of cells. These PSCs have the potential to differentiate into any cell type derived from the three germ layers. ${ }^{1-5}$ Cell type determination is heavily dependent on epigenetic process. The generation of iPCSs from differentiated cells is partly regulated by epigenetics. PSCs provide an unlimited cell source with the potential for use in studying diseases, drug screening, and regenerative medicine. Human PSCs provide a promising platform for obtaining patient-specific cells for various therapeutic and research applications. In general, induced pluripotent stem cells (iPSCs) are generated via genetic manipulation or by nuclear transfer to generate PSCs from somatic cells. ${ }^{6}$ However, nuclear transfer-generated PSCs raised ethical concerns and are technically difficult to prepare. The genetic manipulation of PSCs limits their clinical uses. Although embryonic stem cells (ESCs) do not need to be genetically manipulated, there are strong ethical concerns regarding human ESCs (hESCs), limiting their use in clinical applications.

iPSCs were first generated in 2006-2007 by the transduction of four transcription genes, Oct3/4, Sox 2 , c-Myc, and
Klf- $4^{7-10}$ or Oct 4, Sox2, Nanog, and Lin $28 .{ }^{11}$ Following these studies, several researchers succeeded in generating iPSCs using fewer pluripotent genes. Of note, researchers generated iPSCs without transducing c-Myc, a potent oncogene. ${ }^{12-14}$ Currently, mouse iPSCs (miPSCs) can be generated by reprogramming a single gene, such as Oct $4,{ }^{15,16}$ or with the aid of small or large molecules in place of gene transduction. ${ }^{17-19}$ However, the low reprogramming efficiency of human iPSCs (hiPSCs) is a major drawback. The use of virus-mediated delivery of reprogramming factors, which leads to the permanent integration of oncogenes and potentially harmful genomic alterations, ${ }^{20}$ is a serious concern. The use of genome-integrating viruses could cause insertional mutagenesis and unpredictable genetic dysfunction. ${ }^{9,21}$

Therefore, several reprogramming technologies that do not use viral integration have been developed for iPSC production. ${ }^{22,23}$ These approaches include the use of non-integrating viruses, ${ }^{24-26}$ transposon-based systems, ${ }^{27}$ and the delivery of reprogramming factors on plasmids..$^{22,28-30}$ Adenovirus, lentivirus, Sendai virus, miRNA, and plasmid transfection methods have been reported to generate miPSCs ${ }^{28,31}$ and

\footnotetext{
${ }^{1}$ Department of Chemical and Materials Engineering, National Central University, Jhongli, Taiwan; ${ }^{2}$ Department of Botany and Microbiology, King Saud University, Riyadh, Saudi Arabia; ${ }^{3}$ Institute of Systems Biology and Bioinformatics, National Central University, Jhongli, Taiwan; ${ }^{4}$ Cathay Medical Research Institute, Cathay General Hospital, Taipei, Taiwan; ${ }^{5}$ Department of Medical Microbiology and Parasitology, Universities Putra Malaysia, Slangor, Malaysia; ${ }^{6}$ Department of Chemical Engineering,

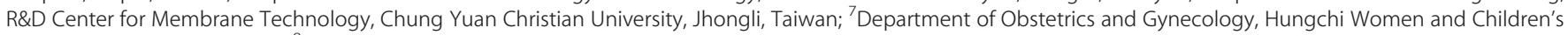
Hospital, Jhongli, Taiwan and ${ }^{8}$ Department of Reproduction, National Research Institute for Child Health and Development, Tokyo, Japan

Correspondence: Professor A Higuchi, PhD, Department of Chemical and Materials Engineering, National Central University, No. 300, Jhongda Road, Jhongli 32001, Taiwan. E-mail: higuchi@ncu.edu.tw
}

${ }^{9}$ These authors contributed equally to this work.

Received 16 June 2014; revised 25 July 2014; accepted 25 July 2014 
hiPSCs $^{24,30,32-35}$ to minimize chromosomal disruption. ${ }^{18}$ $\mathrm{Yu}$ et al. generated hiPSCs by transfecting non-integrating episomal vectors. $^{30}$ In addition, the piggyBac transposon $^{18,27,31}$ and Cre-recombinase excisable viruses ${ }^{36}$ have been used to generate hiPSCs. The transgenes can be excised by inducible gene expression once reprogramming is established. ${ }^{25,27,36}$ However, there is evidence that there can be problems with residual DNA and chromosomal disruptions, resulting in harmful genetic alterations. ${ }^{18}$

The repeated transfection of modified mRNA encoding the reprogramming factors is also efficient for generating iPSCs. ${ }^{22,37}$ Although these strategies eliminate the threat of random viral integration into the host cell genome, these approaches are technically challenging and less efficient than viral transduction. Therefore, it is important to identify new conditions and small or large molecules that can promote reprogramming and ultimately replace all of the reprogramming transcription factors (TFs). ${ }^{14,38-41}$ For clinical applications, using small or large molecules to generate PSCs are preferable to genetic manipulations. Recently, several novel methods have been reported for generation of iPSCs without the use of genetic material; these methods include protein-induced PSCs (piPSCs) that are reprogrammed from somatic cells using cell-penetrating $\mathrm{TF}$ proteins, ${ }^{18,19}$ and chemically iPSCs (CiPSCs) that are reprogrammed from somatic cells using small molecules. ${ }^{14,17,20,38-49}$

Human CiPSCs are a promising tool in the clinical application of PSCs. CiPSCs can be reprogrammed to become iPSCs from somatic cells, without genetic manipulation, through the addition of small-molecule chemicals in the culture medium. In this review, we will discuss the generation of iPSCs without the use of genetic material and instead using small or large (protein) molecules. We will discuss types of small and/or large (protein) molecules that can replace specific viral transduction of pluripotent TFs to obtain piPSCs and CiPSCs from somatic cells.

\section{PSCs REPROGRAMMING WITH PROTEINS (piPSCs)}

In the reprogramming of somatic cells into iPSCs, one of the methods that avoids exogenous genetic introduction to the target cells is delivering the reprogramming proteins directly into cells rather than transducing the cells with TF genes. Previous researchers have reported that the proteins can be delivered into mammalian cells in vitro and in vivo by conjugating the proteins with a short peptide to guide their transduction, such as HIV transactivator of transcription (tat) or polyarginine..$^{30,50-52}$ Various solubilization and refolding techniques have been developed so that recombinant proteins expressed in E. coli and contained in inclusion bodies can be re-folded into bioactive proteins. This allows for easy, large-scale production of therapeutic proteins. ${ }^{30,53}$ Currently, recombinant forms of Oct4, Sox2, Klf4, and c-Myc are commercially available. Table 1 summarizes the reprogramming of mouse and human somatic cells into piPSCs with the aid of proteins by transduction without TFs.
The challenge in delivering proteins into cells is the proteins' limited capacity to penetrate the cell membranes. Proteins that are capable of crossing the cell membrane barrier generally contain high proportions of basic amino acids, such as lysine and arginine..$^{54,55}$ and the HIV tat protein has a short, basic segment of 48-60 amino-acid residues that is known to cross the cell membrane and to activate HIV-specific genes. ${ }^{18,54}$ In 2009, Zhou et al. attached a transfection domain of a polyarginine protein to the $\mathrm{C}$ terminus of the four reprogramming factors Oct4, Sox2, Klf4, and $\mathrm{c}-\mathrm{Myc}$ to generate recombinant proteins that are able to permeate the plasma membranes of mouse embryonic fibroblasts (MEFs). ${ }^{19}$ The mouse piPSCs that were generated were stably expanded for 30 passages, and the morphology of the piPSCs was similar to ESCs, as they formed small, compact, domed colonies. ${ }^{19}$ The piPSCs expressed typical pluripotency markers, including ALP, SSEA1, Nanog, Oct4, and Sox2, as assayed by immunostaining. The expression of endogenous pluripotency genes was verified by RT-PCR. The piPSCs generated embryoid bodies in suspension and differentiated into cells characteristic of the three germ layers: (a) endoderm cells expressing AFP, FoxA2, GATA4, Sox17, albumin (hepatic marker), and Pdx1 (pancreatic marker); (b) mesoderm cells expressing Brachyury and mature beating cardiomyocytes expressing the CT3 and MHC markers; and (c) ectoderm cells expressing Pax5 and Sox1 (neural markers) and $\beta$ III-tubulin and MAP2ab (mature neuronal markers). ${ }^{19}$ Although these findings are promising, the extremely low efficiency $(0.006 \%)$ and poor reproducibility of the generation of piPSCs hinders its use as a general method for generating iPSCs.

The same year, Kim et al. reported the generation of piPSCs from human newborn fibroblasts (HNFs) using four recombinant cell-penetrating reprogramming proteins (Oct4, Sox2, Klf4, and c-Myc) fused with a cell-penetrating peptide (CPP, polyarginine with nine repeating arginine residues). ${ }^{18}$ The authors generated HEK293 cell lines that expressed each of the four human reprogramming proteins fused to CPP. HNFs were treated with cell extracts from the HEK293 cell lines. After repeated treatment with the cell extracts containing the reprogramming proteins, the HNFs ultimately became human piPSCs. ${ }^{18}$ The human piPSCs showed similar characteristics to hESCs (H9) in cell morphology and pluripotent marker expression and were cultured for more than 35 passages without loss of pluripotency, which suggests that the appropriate epigenetic reprogramming events occurred in these cells. The human piPSCs were successively differentiated into cells derived from the three germ layers both in vitro (embryonic formation) and in vivo (teratoma formation).$^{18}$ Interestingly, Kim et al. could not generate mouse piPSCs when they applied the same method to mouse cells. ${ }^{18}$ This discrepancy might be due to a low concentration of reprogramming proteins, as they used whole-protein extracts from HEK293 cells as the source of the reprogramming proteins. Furthermore, Kim et al. did not add 
Table 1 Reprogramming of mouse and human somatic cells into iPSCs with the aid of proteins by transduction without transcription factors (TFs)

\begin{tabular}{|c|c|c|c|c|c|}
\hline TFs required & Somatic cells & PSCS & Small molecules & Efficiency (\%) & Reference \\
\hline \multicolumn{6}{|l|}{ Mouse } \\
\hline No factor & MEFs & miPSCs & VPA, four recombinant proteins (OSKM) with polyarginine tag & $0.006 \%$ & 19 \\
\hline No factor & MEFs & miPSCs & VPA, three recombinant proteins (OSK) with polyarginine tag & $0.002 \%$ & 19 \\
\hline No factor & Mouse dermal fibroblasts & miPSCs & mES (C57) cell line extract & NA & 56 \\
\hline \multicolumn{6}{|l|}{ Human } \\
\hline No factor & Human new born fibroblasts & hiPSCs & $\begin{array}{l}\text { HEK293 Cell extract containing Recombinant } \\
\text { proteins with polyarginine tag }\end{array}$ & $0.001 \%$ & 18 \\
\hline No factor & $\begin{array}{l}\text { Human newborn foreskin } \\
\text { fibroblast BJ (CRL-2522) }\end{array}$ & $\begin{array}{l}\text { hiPSCs } \\
\text { (hiMPCs) }\end{array}$ & Fibromodulin & $0.03 \%$ & 58 \\
\hline
\end{tabular}

small molecules to the culture medium, ${ }^{18}$ whereas Zhou et al. used valproic acid (VPA) for the reprogramming to generate mouse piPSCs. ${ }^{19}$ VPA is known to enhance the reprogramming efficiency of cells to generate miPSCs. ${ }^{42}$

\section{PIPSC GENERATION USING CELL EXTRACTS}

Jin et al. also generated mouse piPSCs using cell extracts instead of viral transduction. They found that cell extracts from only specific ESC lines could promote the reprogramming of mouse dermal fibroblasts into piPSCs. ${ }^{56}$ Therefore, the authors performed protein microarrays to characterize the proteomes of different ESC lines that can and cannot reprogram the mouse dermal fibroblast. Protein extract from the ESC line that could promote reprogramming showed high levels of proteins that regulate protein synthesis and metabolism, compared with the other ESC lines that could not promote reprogramming into piPSCs; this result suggests that there are threshold concentrations of specific synthetic and metabolic proteins that the cells must exceed to initiate reprogramming.

Several researchers have reported that, in addition to ESC extracts, other cell extracts such as fish oocyte extracts ${ }^{57}$ or a single extracellular matrix proteoglycan of fibromodulin ${ }^{58}$ can promote the reprogramming of human fibroblast cells into human piPSCs or induced multipotent stem cells. In most cases, the specific proteins from the extracts that drive reprogramming are unknown. ${ }^{57,59,60}$ Furthermore, it has not yet been verified whether human piPSCs can be reprogrammed with high efficiency and high reproducibility from somatic cells incubated with extracts of hESCs or other animal cells.

\section{COMPARISON OF hIPSCS DERIVED FROM GENETIC MATERIAL AND PROTEINS}

Rhee et al. compared multiple hiPSC lines derived from retrovirus-based, lentivirus-based, and protein-based reprogramming to hESCs based on their capacity to differentiate into neuronal stem cells (NSCs) and dopaminergic neurons. ${ }^{61}$ Optimized co-culturing and fine selection methods led to the efficient generation of NSCs and dopaminergic neurons from hESCs and all hiPSC lines tested, including piPSCs. NSCs and dopaminergic neurons derived from hiPSCs using lentiviral transduction showed residual expression of exogenous reprogramming genes, whereas hiPSCs derived from retroviral vectors and piPSCs did not express the exogenous reprogramming genes. ${ }^{61}$ In addition, the virus-based iPSCs exhibited early cellular senescence and limited expansion because of apoptosis during passaging, whereas hESCs and hiPSCs exhibited unlimited expansion without cellular senescence. NSCs derived from piPSCs were grafted into rats with striatal lesions, a model of Parkinson's disease. NSC engraftment resulted in striking behavioral recovery associated with a high proportion of $\mathrm{TH}^{+}$(ie, dopamine-secreting) neurons, and the transplantation of NSCs rescued motor deficits. However, tumors formed when a large number of NSCs was grafted into the rats. ${ }^{61}$ The researchers also found that fully differentiated dopamine neurons are too vulnerable to survive transplantation; therefore, almost no functional recovery and no $\mathrm{TH}^{+}$ 


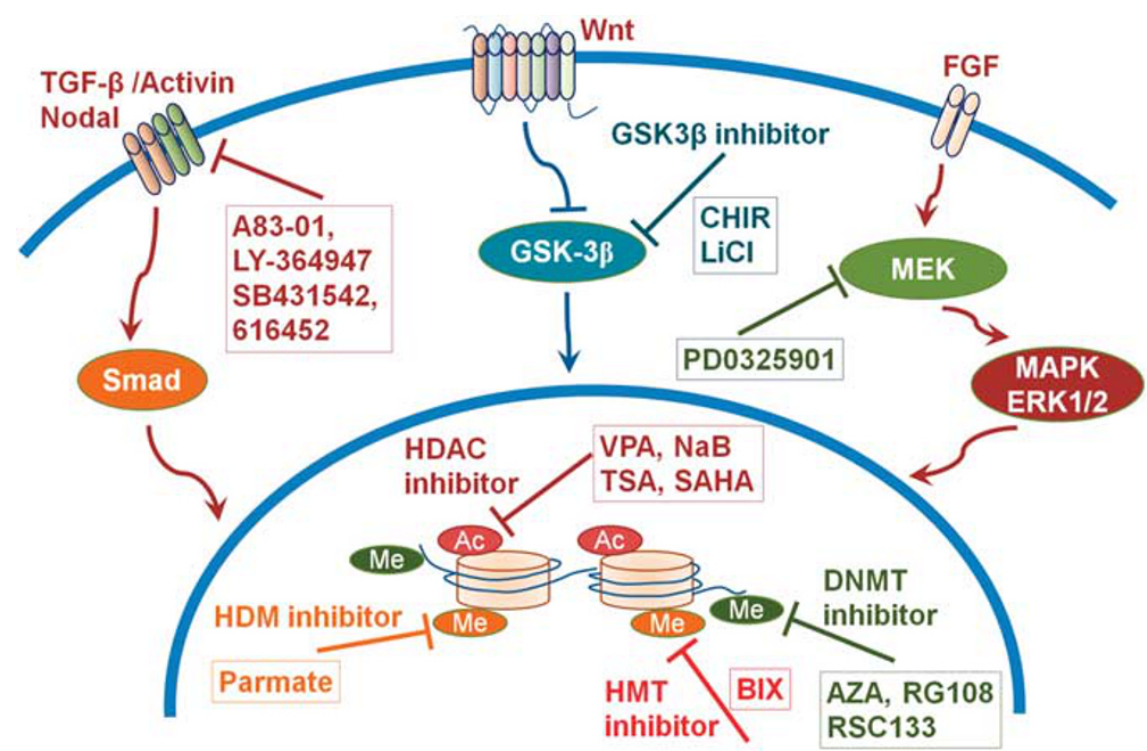

Figure 1 The signaling pathways underlying the chemical manipulation of stem cell fate and reprogramming. Epigenetic modulators can modify the chromatin structure to make it more permissive to changes in the epigenome during reprogramming. Small molecules that target signaling pathways can regulate the expression of pluripotent transcription factor genes, leading to the reprogramming of somatic cells into iPSCs. Several small-molecule inhibitors of epigenetic modification enzymes, such as DNA methyltransferases (DNMTs), histone deacetylases (HADC), histone methyltransferases (HMT), and histone demethylases (HDM) that act as major players in forming the epigenetic landscape, have been selected as small chemical molecules for the reprogramming of somatic cells into iPSCs. The abbreviations of the small molecules are shown in Table 2.

neurons were generated in their study. ${ }^{61}$ This study elegantly described the superiority of hiPSCs generated by virus-free methods, although optimization is still required to remove residual undifferentiated cells and to avoid tumor generation. Such work will pave the way for standardized quality control before moving hiPSCs into clinical trials ${ }^{62}$ and will support the use of human piPSCs in clinical applications, such as personalized cell therapy for specific diseases.

The success of human piPSCs opens an avenue to generate safe production protocols for hiPSCs, as human piPSCs can eliminate the potential risks from the use of viral vectors and DNA transfection. However, the extremely low efficiency of piPSC generation (approximately 0.001\%) is an issue blocking the use of human piPSCs in clinical applications.

\section{SMALL MOLECULES THAT PROMOTE IPSC PRODUCTION INVOLVING FEW TFS}

Small molecules that target specific signaling pathways and/ or functions are valuable chemical tools in the reprogramming of somatic cells into iPSCs. These small molecules have the potential to play extensively important roles in both evaluating the basic biology of stem cells and promoting the development of clinical approaches toward regenerative medicine. Such approaches could open the door to cell replacement therapies, which use functional homogenous cells produced under chemically defined conditions in vitro and the development of small-molecule drugs to stimulate the endogenous patient cells to repair themselves and regenerate. ${ }^{20}$ Here, we review recent progress made in using small molecules to either sustain pluripotency or induce the reprogramming of somatic cells into iPSCs.

Previous studies have demonstrated that the expression of four TFs can reprogram several somatic cell types into iPSCs. Furthermore, iPSCs can be generated by viral integration of Oct4/Sox2/Klf4 without expressing the oncogene $c-M y c$, which contributes to iPSC tumorigenicity, as determined by experiments that generated chimeras and their progeny mice. ${ }^{63}$ For therapeutic usage, it is important to minimize the number of genes transduced into somatic cells to generate iPSCs. ${ }^{64}$ However, decreasing the number of TFs leads to decreased iPSC generation efficiency. Therefore, several small molecules have been developed to enhance the generation efficiency of iPSCs.

Epigenetic changes are important for reprogramming somatic cells into PSCs. Therefore, several small-molecule inhibitors against epigenetic-modifying enzymes that are major players in building the epigenetic landscape, ${ }^{47}$ such as DNA methyltransferases (DNMTs), histone deacetylases (HDACs), histone methyltransferases (HMTs), and histone demethylases, were selected for somatic cell reprogramming into iPSCs. Epigenetic modulators can modify chromatin structure and make it more permissive to transcriptional machinery during somatic cell reprogramming. Some small molecules are summarized in Figure 1, which target transcription factors that are downstream in the signaling pathways. These small molecules can regulate gene expression level of pluripotent TFs, leading to somatic cell reprogramming into iPSCs, and it will be further discussed later in this review. 
Small molecules with molecular weights less than 500-800 Da can freely permeate across the cell membrane and can be used to reprogram somatic cells into iPSCs. ${ }^{65}$ It is systematically approached to identify small molecules to replace the reprogramming TFs or to promote reprogramming efficiency. One high-throughput method used to discover small molecules is as follows. Each well on the plate is seeded with somatic cells that are transduced with Oct4 promoterdriven enhanced green fluorescence protein and subsequently transcription factors, as endogenous Oct4 expression is the first indication that iPSCs are being generated. Next, a panel of small molecules are screened, which can either replace Sox2, Oct4, and/or promote the efficiency of reprogramming. Colony numbers expressing GFP were evaluated as read out of this experiment. The colony generation efficiency is estimated from cells treated with and without small molecules.

Table 2 shows the small molecules that can replace TFs, which are required for reprogramming and increase reprogramming efficiency in generating iPSCs. These small molecules are inhibitors of epigenetic marks and singling pathways.

\section{SMALL MOLECULES THAT CAN REPLACE Oct4}

Oct4 is the master regulatory pluripotency gene and may serve as a pluripotency determinant in reprogramming. ${ }^{15,66-68}$ BIX01294, a G9a HMTase inhibitor, was reported to induce miPSCs in place of Oct4 (Table 2) ${ }^{69}$ Furthermore, Forskolin (FSK, cAMP agonist), D4476 (casein kinase 1 inhibitor), and 2-methyl-5-hydroxytryptamine (5-HT3 agonist) can replace Oct4 in mouse cells with the aid of other small molecules. ${ }^{17}$ RG108, a DNMT inhibitor, can replace Oct4 during mouse skeletal muscle cell reprogramming into miPSCs where skeletal muscle cells endogenously express Sox2, Klf4, and $c-M y c c^{70}$ Figure 2 shows the chemical scheme of small molecules that may functionally replace Oct4 and Klf4 during somatic cell reprogramming into iPSCs.

The compounds 616452 (E-616452) and SB431542 are transforming growth factor (TGF)- $\beta$ inhibitors that could replace Sox2 during mouse and human iPSC generation (Figure 1). ${ }^{15,69-71}$ Compound 616452 can replace Sox2 in the MEF reprogramming. However, 616452 does not actually act by inducing Sox2 expression in the target cells; rather, it enables reprogramming through the induction of Nanog transcription. ${ }^{69}$ Another TGF- $\beta$ inhibitor, LY-364947, can replace Sox2 in miPSC generation (Figure 1). ${ }^{69,72}$ Furthermore, the glycogen synthase kinase-3 (GSK-3) inhibitor CHIR99021 (CHIR), which activates the Wnt signaling pathway, was reported to induce the reprogramming of both mouse and human somatic cells without the use of a Sox2 transgene. ${ }^{71}$ The protein arginine methyltransferase inhibitor AMI-5 enables Oct4-induced reprogramming of MEFs in combination with the TGF- $\beta$ inhibitor A83-01 (A-83-01) and can replace Sox2 during mouse somatic cell reprogramming. ${ }^{73}$ BayK8644 (BayK), an L-channel calcium agonist, was also reported to be able to replace Sox2 in combination with BIX01294 during MEF reprogramming into miPSCs. ${ }^{63} \mathrm{Shh}$, purmorphamine, and oxysterol, the activator of Sonic hedgehog signaling, have been reported to upregulate Bmil, Sox2, and $N-M y c$ expression in mouse fibroblasts. ${ }^{74}$ Therefore, these molecules can replace Sox2 in mouse fibroblast reprogramming into NSCs that are naturally expressing Sox2. ${ }^{74}$

Staerk et al. applied a cell-based, high-throughput chemical screening method to identify small molecules that can replace Sox2 during mouse somatic cell reprogramming. ${ }^{72}$ From their Nanog reporter-based screening, they discovered that the Pan-Src family kinase inhibitors ipyrazine, dasatinib, and PP1 could replace Sox 2 in MEF reprogramming into miPSCs. ${ }^{72}$ Figure 2 also shows the chemical scheme of small molecules that may functionally replace Sox2 during somatic cell reprogramming into iPSCs.

SMALL MOLECULES THAT CAN REPLACE KIf4 and c-Myc Kenpaullone has been reported as a substitute for Klf4 in mouse cells, although the underlying mechanism is unknown. ${ }^{75}$ Furthermore, several small molecules can increase the iPSC generation efficiency, indicating that the small molecules can replace Klf4 and $c-M y c$ during somatic cell reprogramming into iPSCs. For example, VPA (an HDAC inhibitor) improves reprogramming efficiency by more than 100 -fold and enables efficient iPSC induction without the introduction of $c-M y c .^{76}$

\section{SMALL MOLECULES THAT PROMOTE THE EFFICIENCY OF iPSC GENERATION}

Figure 3 shows the chemical scheme of small molecules that promote somatic cell reprogramming into iPSCs. 5-Azacytidine, which is a DNMT inhibitor is reported to facilitate the transition of partially reprogrammed MEFs into fully reprogrammed iPSCs from $0.41 \%$ in partially reprogrammed MEFs to $77.8 \%$ with 5-azacytidine treatment after five passages. ${ }^{77}$

The MEK inhibitor PD0325901 can inhibit the mitogenactivated protein kinase/extracellular signal-regulated kinase signaling pathway to promote late somatic cell reprogramming into mouse and human iPSCs (Figure 1)..$^{20,67,71}$ PD0325901 enhances the efficiency and completion of the iPSC reprogramming process. PD0325901 inhibits the growth of non-iPSC colonies and promotes the growth of reprogrammed iPSCs, leading to larger and more homogeneous iPSC colonies. ${ }^{67}$

Tranylcypromine (brand name: Parnate), an H3K4 demethylation inhibitor, can also promote the reprogramming efficiency of mouse somatic cells into miPSCs (approximately 20 -fold). ${ }^{15}$ Tranylcypromine is also known to activate endogenous Oct4 expression in mouse embryonic carcinoma cells. ${ }^{78}$

Sodium butyrate, a natural small fatty acid and HDAC inhibitor, increases the efficiency of mouse and human iPSC 
Table 2 Small molecules facilitating somatic cell reprogramming and their function

\begin{tabular}{|c|c|c|c|c|c|}
\hline Small molecules & $C^{a}$ & Host animal & Function & TFs to be replaced or function & Reference \\
\hline 5-aza-CR, AZA & $0.5 \mathrm{mM}$ & Mouse & DMNT inhibitor & Promotion of reprogrammming & 77 \\
\hline RG108 & $0.04-500 \mu \mathrm{M}$ & Mouse & DMNT inhibitor & Sox2 (with BIX) or Oct4 & 63 \\
\hline $\mathrm{RSC} 133$ & $10 \mu \mathrm{M}$ & Human & $\begin{array}{l}\text { DMNT inhibitor, Histone } \\
\text { deacetylase inhibitor }\end{array}$ & Promotion of reprogramming & 82 \\
\hline Sodium butyrate & $0.5-1 \mathrm{mM}$ & Mouse, human & HDAC inhibitor & Promotion of reprogramming & 79 \\
\hline SAHA & $5 \mu \mathrm{M}$ & Mouse & HDAC inhibitor & Promotion of reprogramming & 42 \\
\hline TSA & $20 \mathrm{nM}$ & Mouse & HDAC inhibitor & Promotion of reprogramming & 42 \\
\hline VPA & $0.5-2 \mathrm{mM}$ & Mouse, human & HDAC inhibitor & Promotion of reprogramming & 15 \\
\hline Tranylcypromine (Parnate) & $5-10 \mu \mathrm{M}$ & Mouse & $\begin{array}{l}\text { H3K4 demethylation inhibitor } \\
\text { (epigenetic modulator) }\end{array}$ & Promotion of reprogramming & 71 \\
\hline $\mathrm{BIX}$ & $0.5-2 \mu \mathrm{M}$ & Mouse & G9a HMTase inhibitor & Oct4 & 67 \\
\hline $\mathrm{CHIR}$ & $3-10 \mu \mathrm{M}$ & Mouse, human & $\begin{array}{l}\text { GSK-3 } \beta \text { inhibitor that activate } \\
\text { Wnt signalling pathway }\end{array}$ & Sox2 & 15 \\
\hline Kenpaullone & $5 \mu \mathrm{M}$ & Mouse & GSK-3/CDKs inhibitor & Klf4 & 75 \\
\hline Compound B6 & $1 \mu \mathrm{M}$ & Mouse & AKt-mediated inhibitor of GSK3- $\beta$ & Promotion of reprogramming & 84 \\
\hline $\mathrm{LiCl}$ & $5-10 \mathrm{mM}$ & Mouse and human & GSK-3 $\beta$ inhibitor, LSD1 inhibitor & Promotion of reprogramming & 70 \\
\hline 616452 (E-616452, RepSox) & $1 \mu \mathrm{M}$ & Mouse, human & TGF- $\beta$ inhibitor (ALKinhibitor II) & Sox2 & 69 \\
\hline A83-01 & $0.5 \mu \mathrm{M}$ & Mouse, human & TGF- $\beta$ inhibitor & Promotion of reprogramming & 43 \\
\hline LY-364947 & $1 \mu \mathrm{M}$ & Mouse & TGF- $\beta$ inhibitor & Sox2 & 72 \\
\hline SB431542 & $2 \mu \mathrm{M}$ & Mouse, human & TGF- $\beta$ inhibitor & Promotion of reprogramming & 71 \\
\hline PD0325901 (PD) & $0.5-1 \mu \mathrm{M}$ & Mouse, human & MEK inhibitor & Promotion of reprogramming & 67 \\
\hline AMI-5 & $5 \mu \mathrm{M}$ & Mouse & $\begin{array}{l}\text { Protein arginine methyltransferase } \\
\text { inhibitor }\end{array}$ & Sox2, KIf4 (with A-83-01) & 73 \\
\hline N-oxaloylglycine & $1 \mu \mathrm{M}$ & Human & Prolyl-4-hydroxylase inhibitor & Promotion of reprogramming & 43 \\
\hline Compound B4 (TGFb-RI ) & $1 \mu \mathrm{M}$ & Mouse & ALK4 inhibitor & Promotion of reprogramming & 84 \\
\hline Dasatinib & $0.5 \mu \mathrm{M}$ & Mouse & Src family tyrosine kinase inhibitor & Sox2 & 72 \\
\hline iPY razine (iPY) & $10 \mu \mathrm{M}$ & Mouse & Src family tyrosine kinase inhibitor & Sox2 & 72 \\
\hline PP1 & $10 \mu \mathrm{M}$ & Mouse & Src family tyrosine kinase inhibitor & Sox2 & 72 \\
\hline Rapamycin & $0.3 \mathrm{nM}$ & Mouse & mTOR inhibitor & Promotion of reprogramming & 83 \\
\hline Compound B8 & $1-2 \mu \mathrm{M}$ & Mouse & IP3K inhibitor & Promotion of reprogramming & 84 \\
\hline Compound B10 & $1-2 \mu \mathrm{M}$ & Mouse & P38 kinase inhibitor & Promotion of reprogramming & 84 \\
\hline D4476 & $5 \mu \mathrm{M}$ & Mouse & CK1 inhibitor & Oct 4 with FSK and 2-Me-5HT & 17 \\
\hline BayK & $2 \mu \mathrm{M}$ & Mouse & a L-channel calcium agonist & Sox2 & 63 \\
\hline FSK & $10-50 \mu \mathrm{M}$ & Mouse & CAMP agonist & Oct4 with 2-Me-5HT), and D4476 & 17 \\
\hline Prostaglandin E2 & $5 \mu \mathrm{M}$ & Mouse & cAMP agonist & Promotion of reprogramming & 17 \\
\hline Rolipram & $10 \mu \mathrm{M}$ & Mouse & CAMP agonist & Promotion of reprogramming & 17 \\
\hline 2-Me-5HT & $5 \mu \mathrm{M}$ & Mouse & 5-HT3 agonist & Oct4 with FSK and D4476 & 17 \\
\hline $\begin{array}{l}\text { 5-(4-Chloro-phenyl)-3-phenyl- } \\
\text { pent-2-enoic acid (PS48) }\end{array}$ & $5 \mu \mathrm{M}$ & human & PDK1 activator & Promotion of reprogramming & 43 \\
\hline 8-Br-cAMP & $0.1-0.5 \mathrm{mM}$ & Human & $\begin{array}{l}\text { CAMP-dependent protein } \\
\text { kinase activator }\end{array}$ & Promotion of reprogramming & 65 \\
\hline Fructose 2,6-bisphosphate & $10 \mathrm{mM}$ & Human & Phosphofructokinase 1 activator & Promotion of reprogramming & 43 \\
\hline Quercetin & $1 \mu \mathrm{m}$ & Human & $\begin{array}{l}\text { Hypoxia-inducible factor } \\
\text { pathway activator }\end{array}$ & Promotion of reprogramming & 43 \\
\hline
\end{tabular}


Table (Continued)

\begin{tabular}{lllll}
\hline Small molecules & $C^{\mathrm{a}}$ & Host animal & Function & TFs to be replaced or function \\
\hline DZNep & $0.05-0.1 \mu \mathrm{M}$ & Mouse & Epigenetic modulators & Promotion of reprogramming \\
DNP & $1 \mu \mathrm{M}$ & Human & Oxidative phosphorylation uncoupler & Promotion of reprogramming \\
TTNPB & $1 \mu \mathrm{M}$ & Mouse & Retinoic acid receptor ligand & Promotion of reprogramming \\
Oxysterol & $0.5-1 \mu \mathrm{M}$ & Mouse & Sonic hedgehog signaling & Sox2, Klf4, and C-Myc \\
Purmorphamine & $0.5-1 \mu \mathrm{M}$ & Mouse & Sonic hedgehog signaling & Sox2, Klf4, and C-Myc \\
Shh & $500 \mathrm{ng} / \mathrm{ml}$ & Mouse & Sonic hedgehog signaling & Sox2, Klf4, and C-Myc \\
\hline
\end{tabular}

Abbreviations: BayK, Bay K8644; BIX, BIX-01294; CHIR, CHIR99021; CK1, Casein kinase 1; DNMT, DNA methyltransferase; DNP, 2,4-dinitrophenol; DZNep, 3-deazaneplanocin; FSK, forkolin; HDAC, histon deacetylase; G9a HMTase, G9a histone methyltransferase; IP3K, inositol triphosphate 3-kinase; PDK1, 3'-phosphoinositide-dependent kinase 1; SAHA, suberoylanilide hydroxamic acid; TF, transcription factor; TSA, trichostain A; VPA, valproic acid; 2-Me-5HT, 2-methyl-5hydroxytryptamine; 5-aza-CR, AZA, 5-azacytidine; 8-Br-cAMP, 8-Bromoadenosine $3^{\prime \prime} 5^{\prime \prime}$-cyclic monophosphate.

${ }^{a} C$; Concentration used typical reprogramming experiments.

cell generation over a range of concentrations, such as $0.5-$ $1 \mathrm{mM}^{79,80}$ The effect of sodium butyrate on reprogramming seems to be mediated by $c-M y c$ and works during an early stage of reprogramming. In addition, sodium butyrate enhances the percentage of fully reprogrammed iPSCs by reducing the number of incomplete or partially reprogrammed cells. ${ }^{79}$ Genome-wide gene expression analysis suggests that the upregulation of several pluripotent genes in sodium butyrate-treated MEFs during reprogramming is not through the suppression of the p53-p21 pathway, even though reprogramming efficiency is also known to be increased by the suppression of the p53-p21 pathway. ${ }^{80}$

The anti-psychotic drug lithium chloride ( $\mathrm{LiCl}$ ) can accelerate the generation of mouse and human iPSCs. ${ }^{70}$ The effect of $\mathrm{LiCl}$ on promoting reprogramming is partially dependent on its role as a GSK-3 $\beta$ inhibitor. However, $\mathrm{LiCl}$ also upregulates Nanog, which has not been observed after the treatment of somatic cells with other GSK- $3 \beta$ inhibitors. Furthermore, $\mathrm{LiCl}$ exerts its effects by promoting epigenetic modifications via the downregulation of LSD1, an H3K4specific HDAC gene. ${ }^{70}$

PS48, an activator of 3-phosphoinositide-dependent protein kinase 1, can also accelerate the reprogramming efficiency into hiPSCs. ${ }^{40}$ PS48 activates the phosphatidylinositol 3-kinase/Akt pathway and significantly induces the expression of glycolytic genes, which results in the facilitation of metabolic reprogramming from the mitochondrial oxidation process used mainly by adult somatic cells into the glycolysis process used in PSCs. ${ }^{40,43}$ Owing to its lower oxidative stress, glycolytic metabolism is favorable over mitochondrial respiration in PSCs during cell proliferation and cell-cycle transition. The hypoxic condition and its effector gene, hypoxia-inducible factor $1 \alpha$, which is extensively linked to promoting glycolytic metabolism, can also enhance the reprogramming efficiencies of both mouse and human cells. ${ }^{40,81}$

Several other small molecules, such as A83-01 (TGF- $\beta$ inhibitor), ${ }^{43,70} 3$-deazaneplanocin (epigenetic modulator), ${ }^{17}$ 2,4-dinitrophenol (DNP, oxidative phosphorylation uncoupler), ${ }^{43}$ RSC133 (DNMT inhibitor), ${ }^{82}$ rapamycin (mTOR inhibitor), ${ }^{83}$ compound B6 (AKT-mediated inhibitor of GSK3- $\beta$ ), ${ }^{84}$ compound B8 (inositol triphosphate 3-kinase inhibitor), ${ }^{84}$ compound B10 (P38 kinase inhibitor), ${ }^{84}$ and vitamin $\mathrm{C},{ }^{70}$ can facilitate the reprogramming efficiency of somatic cells into mouse and/or human iPSCs (Table 2).

\section{SMALL MOLECULES CAN REPLACE SEVERAL TFS DURING MOUSE IPSC REPROGRAMMING}

From the available knowledge of small molecules that can substitute for the essential TFs Oct4, Sox2, Klf4, and $c-M y c$, and promote reprogramming efficiency, several researchers tried to generate iPSCs by reducing the numbers of the TFs transduced into mammalian somatic cells. Figure 4 shows the schematic representation of some of the processes developed for miPSC generation from MEFs by reducing the numbers of TFs with and without small molecules. Table 3 summarizes the research for mouse somatic cell reprogramming into miPSCs by transduction with and without TFs and with the aid of small molecules.

NSCs and keratinocytes are known to endogenously express Sox2, Klf4, and/or $c-M y c$ to some extent. Some examples of the gene expression levels of Oct4, Sox2, and Nanog in human fibroblasts, keratinocytes, CD133 ${ }^{+}$cells from cord blood, and NSCs are described in Figure 5. ${ }^{13,85,86}$ Several researchers tried to use endogenously expressing Sox2, Klf4, and/or $c-M y c$ and to generate iPSCs with fewer numbers of pluripotent TFs. Kim et al. succeeded in preparing miPSCs from mouse NSCs using two exogenous TFs (Oct4 and Klf4 or Oct4 and $c-M y c) .{ }^{87}$ They did not use small molecules to enhance reprogramming efficiency. Shi et al. also generated iPSCs from mouse NSCs using the G9a HMTase inhibitor BIX-01294 (BIX) in conjunction with the transduction of Oct4 and Klf4, but without the use of oncogenic $c-M y c{ }^{67}$ BIX induced Oct4 overexpression and facilitated the depression of Oct4, which promoted the iPSC reprogramming efficiency. ${ }^{20,67}$ 
a

Small molecules replacing Oct4<smiles>[R9][R19]([H])([H])C1C(=O)N([C@H](Cc2c[nH]c3ccccc23)C(=O)O)C(=O)c2ccccc21</smiles><smiles>COc1cc2nc(N3CCCN(C)CC3)nc(NC3CCN(Cc4ccccc4)CC3)c2cc1OC(=O)OCc1ccccc1</smiles>

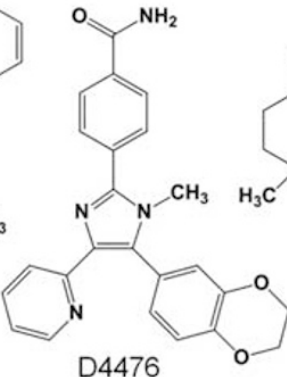<smiles>C=CC1(C)CC(=O)C2(C)OC3(OC(C)=O)C(OC(C)=O)C(O)C4C(C)(C)CCC(O)C4(O)C23C1</smiles>

2-methyl-5-hydroxytryptamine

b<smiles>O=C1Cc2c([nH]c3ccc(Br)cc23)-c2ccccc2N1</smiles>

Kenpaullone<smiles>CC(C)(C)C(C)(C)C</smiles>

c Small molecules replacing Sox2

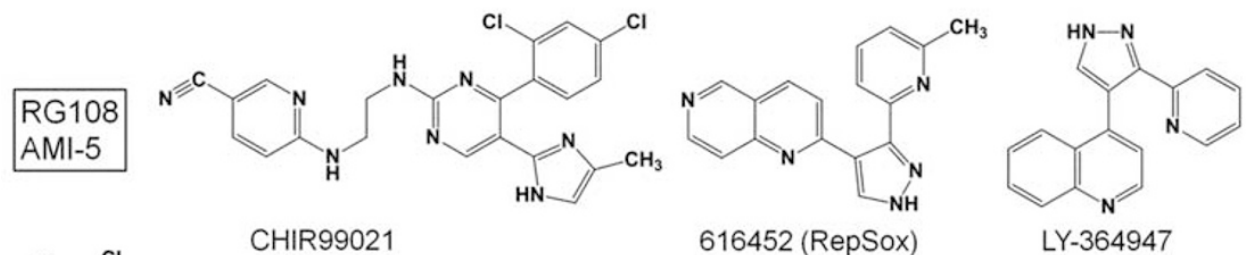<smiles>Cc1ccc(-c2nn(C(C)(C)C)c3ncnc(N)c23)cc1</smiles>
CHIR99021 616452 (RepSox)

LY-364947<smiles>COC(=O)C1=C(C)CC(C)=C([N+](=O)[O-])C1c1ccccc1C(F)(F)F</smiles>

Figure 2 Representative schematic structures of small molecules that can replace Oct4, Klf4, and Sox2 transduction in reprogramming to generate iPSCs. (a) Small molecules replacing Oct4; (b) small molecules replacing KIf4; (c) small molecules replacing Sox2.

Silva et al. also prepared miPSCs from mouse brain-derived NSCs using Oct4 and Klf4 transduction. ${ }^{88}$ The cells rapidly adopted an undifferentiated morphology after a single round of transduction. However, these cells were partially reprogrammed and did not stably express endogenous Oct4 or Nanog, and they were unable to colonize chimeras. ${ }^{88}$ Therefore, the authors cultured the partially reprogrammed cells in medium containing a dual inhibitor of mitogen-activated protein kinase signaling and GSK-3, 2i medium, along with leukemia inhibitory factor, which is a self-renewal cytokine for mouse PSCs. ${ }^{8}$ The cells cultured in $2 \mathrm{i}$ medium with leukemia inhibitory factor induced the stable upregulation of Oct4 and Nanog, transgene silencing, and competence for somatic and germline chimerism, which demonstrated that the cells were completely reprogrammed into miPSCs. ${ }^{88}$ $2 \mathrm{i}$ medium is a powerful tool for generating miPSCs and 


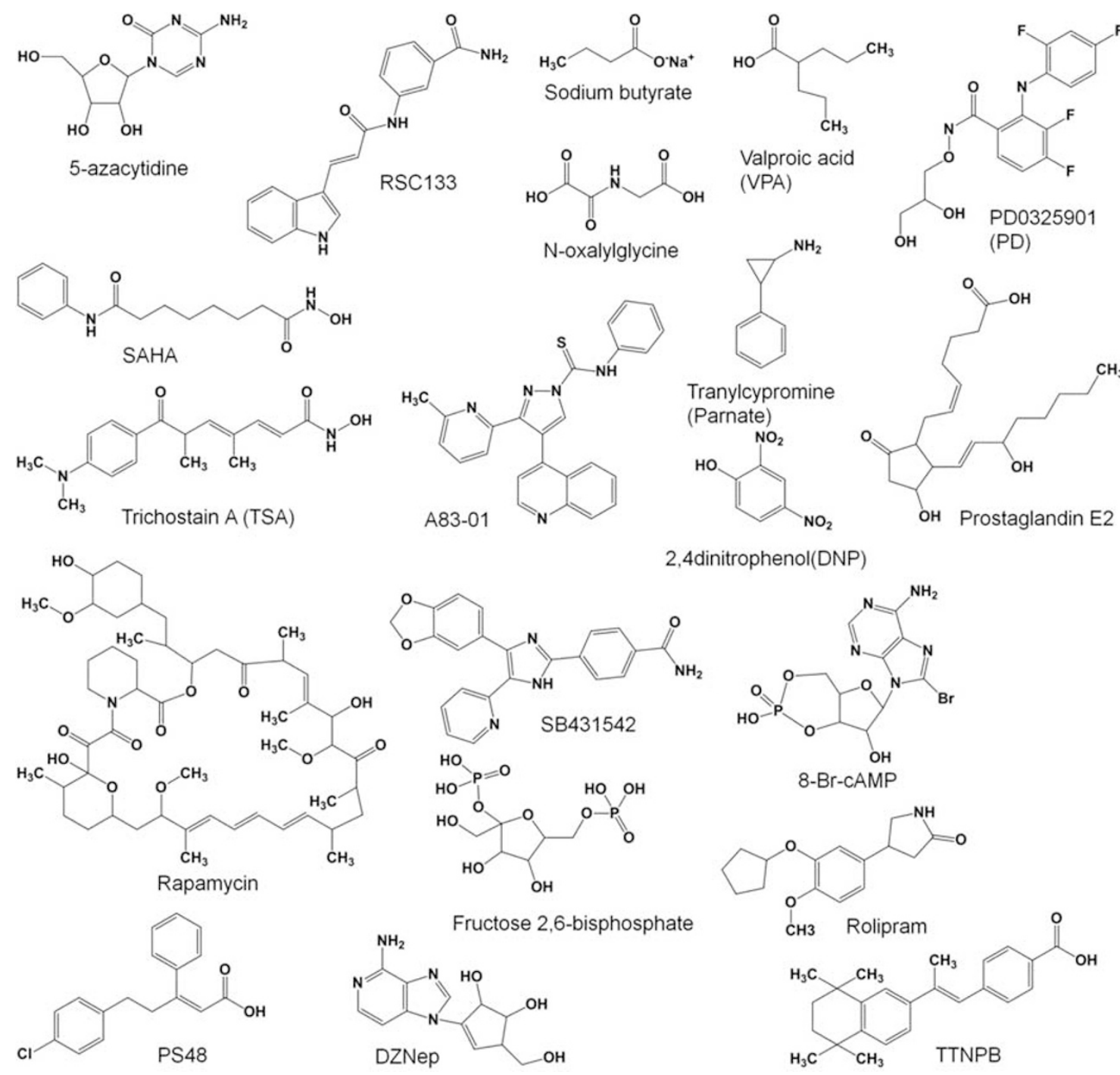

Figure 3 Representative schematic structures of small molecules that promote reprogramming to generate iPSCs.

seems to aid in the completion of mouse somatic cell reprogramming into miPSCs, although the effect of $2 \mathrm{i}$ medium on the generation of hiPSCs is currently unclear.

Other groups have also examined whether they could generate miPSCs from other somatic cells that do not endogenously express pluripotent TFs, such as MEFs, using small molecules and transducing fewer TFs. Huangfu et al. reprogrammed MEFs into miPSCs using VPA and transducing three factors without introducing the oncogene $c-M y c$. VPA, an HDAC inhibitor, improved the reprogramming efficiency by more than 100 -fold under their conditions. ${ }^{42}$

Shi et al. screened several drugs to identify small molecules that can generate iPSCs from MEFs transduced with Oct4 and Klf4 and thus compensate for the lack of Sox2 overexpression. ${ }^{63}$ They found that a combination of BIX and Bayk8644 (BayK), an L-channel calcium agonist, was effective at compensating for the lack of Sox2 expression. ${ }^{63}$ This combination of small molecules (BIX and BayK) enabled the reprogramming of Oct4/Klf4-transduced MEFs, which do not endogenously express the TFs (ie, Oct4, Sox2, and Klf4) essential for reprogramming into iPSCs. ${ }^{7,8}$ RG108, a DNMT inhibitor, can act as a direct epigenetic modifier to shift epigenetic landscapes for cell reprogramming. In combination with BIX, RG108 can reprogram cells transduced with Oct4 and Klf4 into miPSCs with high efficiency. ${ }^{20,63}$

VPA and CHIR99021 can improve the efficiency of miPSC colony generation after the transduction of three factors into MEFs, and Sox 2 can be replaced by the TGF- $\beta$ inhibitor $616452 .{ }^{15}$ Therefore, Li et al. also generated miPSCs using only two TFs, Oct4 and Klf4, in combination with VPA, CHIR99021, and 616452. ${ }^{15}$ The authors further discovered that miPSC colonies were generated using only one TF, Oct4, in combination with VC6 (VPA, CHIR99021, and 616452) 


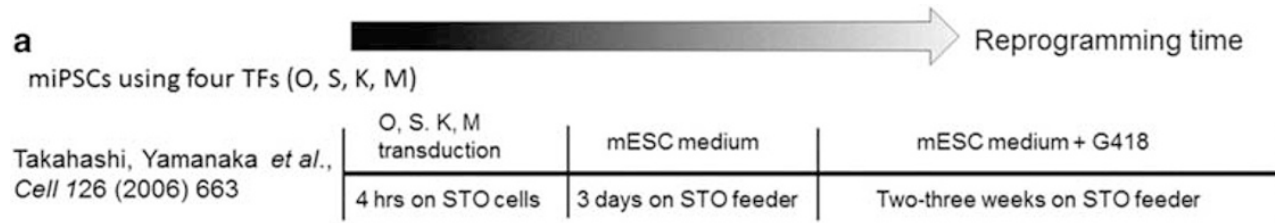

b

miPSCs using three TFs $(O, S, K)$

\begin{tabular}{|c|c|c|c|}
\hline \multirow{2}{*}{$\begin{array}{l}\text { Huangfu et al., } \\
\text { Nat Biotech } 26 \text { (2008) } 795\end{array}$} & $\begin{array}{l}\mathrm{O}, \mathrm{S}, \mathrm{K} \\
\text { transduction }\end{array}$ & $\begin{array}{l}\text { mESC medium with } \\
\text { VPA }\end{array}$ & mESC medium \\
\hline & 2 days on dishes & 7 days on MEF feeder & Culture on MEF feeder \\
\hline
\end{tabular}

C miPSCs using three $\operatorname{TFs}(\mathrm{O}, \mathrm{K})$

\begin{tabular}{|c|c|c|c|c|}
\hline \multirow{2}{*}{$\begin{array}{l}\text { Shi et al., } \\
\text { Cell Stem Cell } 3 \text { (2008) } 568\end{array}$} & $\begin{array}{l}\mathrm{O}, \mathrm{K} \\
\text { transduction }\end{array}$ & $\begin{array}{l}\text { mESC medium with } \\
\mathrm{BIX}\end{array}$ & $\begin{array}{l}\text { mESC medium with } \\
\mathrm{BIX} \text { BayK }\end{array}$ & mESC medium \\
\hline & $12-14 \mathrm{hrs}$ on Matrigel & 5 days on Matrigel & $9-16$ days on Matrigel & Culture on \\
\hline
\end{tabular}

d

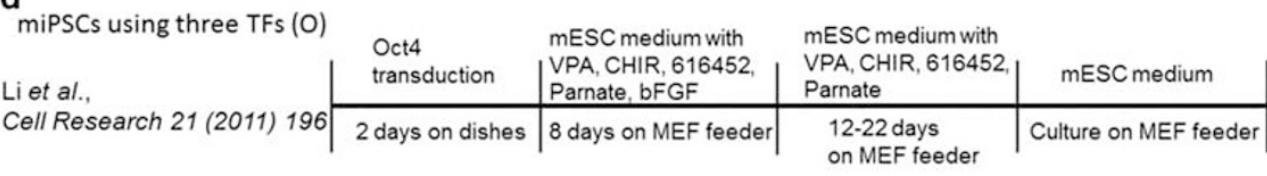

e miPSCs using three TFs (O)

Moon et al., Cell Res 21 (2011) 1305

\begin{tabular}{|l|c|c|}
\multicolumn{1}{|l}{$\begin{array}{l}\text { Repe medium with } \\
\text { Shh, Pur, Oxysterol }\end{array}$} & $\begin{array}{l}\text { Oct4 transduction with } \\
\text { Shh, Pur, Oxtsterol }\end{array}$ & mESC medium \\
\hline 1 days on dishes & 2 days on dishes & Culture on MEF feeder
\end{tabular}

f miPSCs using no TF

Hou et al., Science 341 (2013) 651

mESC medium with
\begin{tabular}{|l|l|l|l|}
$\begin{array}{l}\text { VPA, CHIR, 616452, } \\
\text { parnate, forkolin }\end{array}$ & $\begin{array}{l}\text { CHIR, 616452, parmate, } \\
\text { forkolin, DZNep, TTNPB }\end{array}$ & $\begin{array}{l}\text { mESC medium with } \\
\text { PD, CHIR (2i medium) }\end{array}$ & mESC medium \\
\hline $16-20$ days on dishes & $12-16$ days on dishes & Culture on dishes & $\begin{array}{l}\text { Culture on MEF } \\
\text { feeder }\end{array}$
\end{tabular}

Figure 4 Schematic representation of the process of miPSC generation from MEFs by reducing the number of TFs with and without small molecules. (a) miPSCs using four TFs (Oct4 [O], Sox2 [S], Klf4 [K], and c-Myc [M] ); ${ }^{7}$ (b) miPSCs using three TFs $(\mathrm{O}, \mathrm{S}, \mathrm{K}){ }^{42}$ (c) miPSCs using two TFs $(\mathrm{O}, \mathrm{K}) ;{ }_{i}^{63}(\mathbf{d}$, e) miPSCs using one TF (O); ${ }^{15,74}$ and (f) miPSCs using no TFs. ${ }^{17}$

treatment when MEFs and adult mouse fibroblasts were cultured for 30 days. However, the efficiency was only $0.0005 \%$ (one colony in $2 \times 10^{5}$ cells). ${ }^{15}$ They confirmed that miPSCs could not be generated in the absence of VPA, CHIR 99021, or 616452 in their experiments. ${ }^{15}$ Because tranylcypromine significantly promoted miPSC generation by approximately 20 -fold, $\mathrm{Li}$ et al. succeeded in generating miPSCs by transduction of Oct4 alone with the addition of VPA, CHIR99021, 616452, and tranylcypromine (VC6T) in the culture medium. ${ }^{15}$ It is thought that the small-molecule combination including VC6T facilitated miPSC generation by lowering several major barriers to the reprogramming process. VPA (an HDAC inhibitor) and tranylcypromine (an H3K4 demethylation inhibitor) are epigenetic modulators that have been reported to facilitate iPSC generation. ${ }^{42,89}$ From the effects of VPA and tranylcypromine, H3K4 demethylation and HDAC may be two major epigenetic barriers in the generation of miPSCs, suppressing the pluripotency transcriptional network. GSK3- $\beta$ inhibition by CHIR99021 or TGF- $\beta$ signaling inhibition by 616452 could efficiently replace Sox2 for reprogramming. ${ }^{15}$ GSK3- $\beta$ and TGF- $\beta$ signaling should also be another two critical barriers that suppress the reprogramming process. Therefore, overcoming these four major reprogramming barriers, ie, two epigenetic barriers and two signaling barriers, may allow researchers to generate miPSCs by Oct4 induction alone. ${ }^{15}$

\section{MIPSC GENERATION USING ONE TF}

Yuan et al. generated miPSCs from MEFs using only one factor, Oct4. They treated MEFs with a combination of small molecules, including AMI-5, a protein arginine methyltransferase inhibitor, and A83-01, a TGF- $\beta$ inhibitor, to generate miPSCs. ${ }^{73}$ miPSCs were able to generate live-born pups through tetraploid complementation assays, indicating 
Table 3 Reprogramming of mouse somatic cells into miPSCs by transduction with and without transcription factors (TFs) with the aid of small molecules

\begin{tabular}{|c|c|c|c|c|}
\hline TFs required ${ }^{a}$ & Somatic cells & PSCS & Small molecules & Efficiency (\%) \\
\hline \multicolumn{5}{|l|}{ Four factors } \\
\hline OSKM & MEFs & miPSCs & None & $0.02 \%$ \\
\hline OSKM & $\begin{array}{l}\text { Mouse hepatocyte and } \\
\text { gastric epithelial cells }\end{array}$ & miPSCs & None & $0.01 \%$ \\
\hline OSKM & Mouse liver and stomach cells & miPSCs & None & $0.01 \%$ \\
\hline OSKM & MEFs & miPSCs & Compound B6, B8, and/or B10 & $0.14-0.35 \%$ \\
\hline \multicolumn{5}{|l|}{ Three factors } \\
\hline KSM & Mouse NPCs & miPSCs & None & $0 \%$ \\
\hline $\mathrm{KSM}$ & Mouse NPCs & miPSCs & $\mathrm{BIX}$ & $0.004 \%$ \\
\hline OSK & MEFs & miPSCs & None & $0.001-0.0026 \%$ \\
\hline OSK & MEFs & miPSCs & VPA & $0.089 \%$ \\
\hline OSK & MEFs & miPSCs & $\mathrm{CHIR}$ & $0.18 \%$ \\
\hline
\end{tabular}

Two factors

$\begin{array}{llll}\text { OK } & \text { Mouse NPCs } & \text { miPSCs } & \text { None } \\ \text { OK } & \text { Mouse NPCs } & \text { miPSCs } & \text { BIX } \\ \text { OK } & \text { Mouse NPCs } & \text { miPSCs } & \text { PD + CHIR (2i) } \\ \text { OK } & \text { MEFs } & \text { miPSCs } & \text { None } \\ \text { OK } & \text { MEFs } & \text { miPSCs } & \text { BIX/BayK } \\ \text { OK } & \text { MEFs } & \text { miPSCs } & \text { CHIR } \\ \text { OK } & \text { MEFs } & \text { miPSCs } & 616452 \\ \text { OK } & \text { MEFs } & \text { miPSCs } & \text { VPA, CHIR, } 616452\end{array}$

$\begin{array}{cc}0.004-0.006 \% & 87 \\ 0.034 \% & 67 \\ 0.0125 \% & 88 \\ 0.003 \% & 69 \\ 0.022 \% & 63 \\ 0.006 \% & 71 \\ 0.05 \% & 69 \\ 0.01-0.04 \% & 15\end{array}$

One factor

$\begin{array}{ll}\mathrm{O} & \text { Mouse NPCS } \\ \mathrm{O} & \text { MEFs } \\ \mathrm{O} & \text { MEFs } \\ \mathrm{O} & \text { MEFs } \\ \mathrm{O} & \text { MEFs }\end{array}$

$\begin{array}{ll}\text { miPSCs } & \text { None } \\ \text { miPSCs } & \text { None } \\ \text { miPSCs } & \text { VPA, CHIR, 616452, Parnate } \\ \text { miPSCs } & \text { AMI-5, A-83-01 } \\ \text { miPSCs } & \text { Shh, purmorphamine, or oxysterol }\end{array}$

$\begin{array}{cc}0.004 \% & 16 \\ 0 \% & 15 \\ 0.05-0.08 \% & 15 \\ 0.02 \% & 73 \\ 0.11 \% & 74\end{array}$

No factor

\begin{tabular}{llllll} 
No factor & Mouse skeletal myoblasts & miPSCs & RG108 & $0.11 \%$ & 68 \\
No factor & MEFs & miPSCs & VPA, CHIR, 616452, Parnate, Forkolin, DZNep & $0.04 \%$ & 17 \\
No factor & MEFs & miPSCs & VPA, CHIR, 616452, Parnate, Forkolin, DZNep, TTNPB & $0.2 \%$ & 17 \\
\hline
\end{tabular}

${ }^{\mathrm{a}} \mathrm{O}, \mathrm{S}, \mathrm{K}$, and M indicate Oct4, Sox2, Klf-4, and c-Myc, respectively.

that the miPSCs achieved full reprogramming. Their study suggests that the regulation of protein arginine methylation by inhibition with A83-01 is also involved in the reprogramming process into miPSCs. ${ }^{73}$ The efficiency of miPSC generation was reported to be $0.02 \%$ in their study. ${ }^{73}$
Moon et al. also generated miPSCs from mouse fibroblasts using only one factor, Oct4, with the aid of the small molecules of Shh, purmorphamine, and oxysterol. ${ }^{74}$ These small molecules can activate sonic hedgehog signaling, which compensates for Bmil gene expression. Bmil expression in 


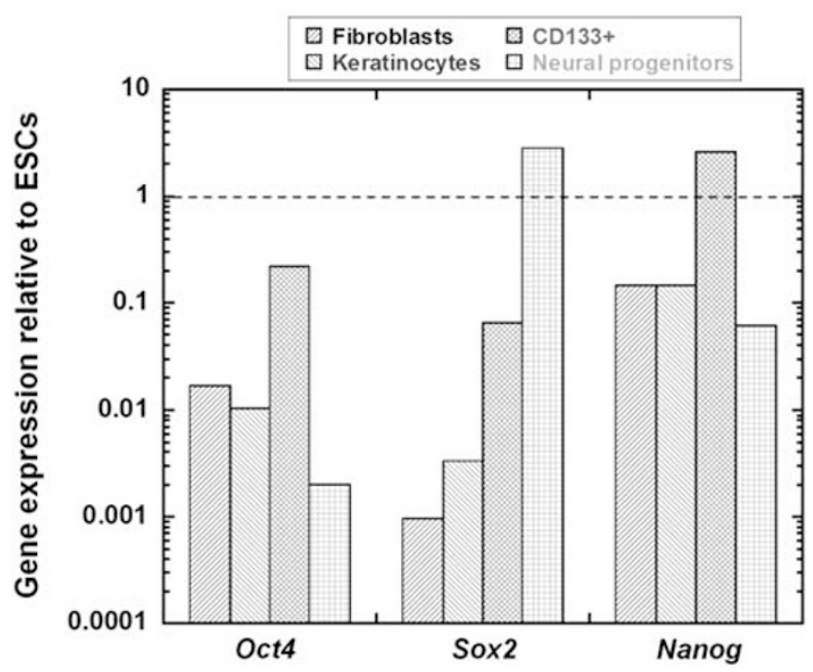

Figure 5 Relative gene expression levels of Oct4, Sox2, and Nanog in human fibroblasts, keratinocytes, $\mathrm{CD} 133^{+}$cells from cord blood, and NSCs. The relative gene expression levels in fibroblasts, keratinocytes, and $\mathrm{CD}_{133^{+}}$cells compared with hESCs were calculated from the data reported by Giorgetti et al. ${ }^{85}$ and Page et al. ${ }^{86}$ The relative gene expression levels in human NSCs compared with hESCs were used from the data reported by Kim et al. ${ }^{13}$

mouse fibroblasts leads to transdifferentiation of mouse fibroblasts into NSC-like cells, which can be subsequently reprogrammed into miPSCs by the transduction of Oct4. ${ }^{74}$ The efficiency of miPSC generation was found to be $0.11 \%$ in their study. ${ }^{74}$

\section{MOUSE CIPSC GENERATION USING SMALL-MOLECULE COCKTAILS}

Hou et al. prepared miPSCs solely using a combination of seven small-molecule compounds that are chemically defined without using transduction or transfection of TFs. ${ }^{17}$ It is difficult to select adequate small molecules that can replace the master regulatory gene Oct4. Therefore, Hou et al. first searched for small molecules that enabled MEF reprogramming in the absence of Oct4 using MEFs expressing Oct4 promoter-driven GFP to identify small molecules that facilitate cell reprogramming. ${ }^{17}$ They identified FSK, 2-methyl-5-hydroxytryptamine, and D4476 as chemical substitutes for Oct4 after screening up to 10000 small molecules, and they chose to use FSK as the chemical substitute of Oct4 in their research. ${ }^{17}$ Because they had already developed the protocol to generate miPSCs using a small-molecule cocktail, 'VC6T' (VPA, CHIR99021, 616452, and tranylcypromine), with a single-gene transduction of Oct $4,{ }^{15}$ they developed mouse CiPSCs using small-molecule cocktails in the absence of the transduction or transfection of small molecules. They used a four-step protocol to generate mouse CiPSCs (Figure 4f). (a) MEFs were first cultured with mESC medium containing VPA, CHIR99021, 616452, tranylcypromine, and FSK (VC6FT) for 16-20 days. (b) The cells were then cultured with mESC medium containing VC6FT, 3-deazaneplanocin (DZNep, epigenetic modulator), and TTNPB (a synthetic retinoic acid receptor ligand). In these cells, the expression levels of most of the pluripotency marker genes were elevated but appeared to still be lower than those found in mESCs, which indicated a partially reprogrammed cell state. (c) In the third stage, the cells were cultured in mESC medium containing PD0325901 and CHIR99021 (2i medium), which promotes complete cellular reprogramming. (d) The colonies exhibiting mESC-like morphologies were shifted onto MEFs and cultured in mESC medium. ${ }^{17}$ The reprogramming efficiency was as high as $0.2 \% .{ }^{17}$ CiPSCs prepared in this research resembled mESCs in terms of their gene expression profiles, epigenetic status, and potential for differentiation and germline transmission. This research suggests that exogenous 'master genes' are dispensable for generating miPSCs using small molecules. This chemical reprogramming strategy opens the door to generate functional, desirable cell types for clinical applications, provided we can succeed in generating human CiPSCs in the future.

\section{SMALL MOLECULES CAN INDUCE HUMAN IPSCS IN COMBINATION WITH A FEW TFS}

Small molecules successively promote the generation of miPSCs by reducing the numbers of TFs required, as shown in the previous section. Researchers started to investigate the generation of hiPSCs by reducing the numbers of TFs with the aid of small molecules. Figure 6 illustrates some schematic representations of the process of hiPSC generation from human somatic cells. Table 4 summarizes reported studies for human somatic cell reprogramming into hiPSCs by transduction with and without TFs in combination with small molecules. Only a few small molecules have been reported to promote reprogramming and/or to replace TFs during hiPSC generation compared with miPSC generation. These molecules for hiPSC generation include sodium butyrate (HDAC inhibitor), VPA (HDAC inhibitor), CHIR99021 (GSK3- $\beta$ inhibitor), LiCl (GSK3- $\beta$ inhibitor), 616452 (TGF- $\beta$ inhibitor), SB431542 (TGF- $\beta$ inhibitor), PD325901 (MEK inhibitor), N-oxaloylglycine (prolyl-4hydroxylase inhibitor), PS48 (3-phosphoinositide-dependent protein kinase 1 activator), 8-Br-cAMP (cAMP-dependent protein kinase activator), fructose 2,6-bisphosphate (phosphofructokinase 1 activator), quercetin (hypoxia-inducible factor pathway activator), and 2,4-dinitrophenol (oxidative phosphorylation uncoupler; Table 2). It will be important to evaluate whether other small molecules that have biological activities in miPSC reprogramming are valid for use in hiPSC reprogramming.

Currently, the minimum transduction of Oct4 in combination with chemically defined small molecules is necessary to generate hiPSCs. This requirement is because the efficiency of hiPSC generation is much less than that of miPSC generation (eg, 0.0005-0.01\%). 
b

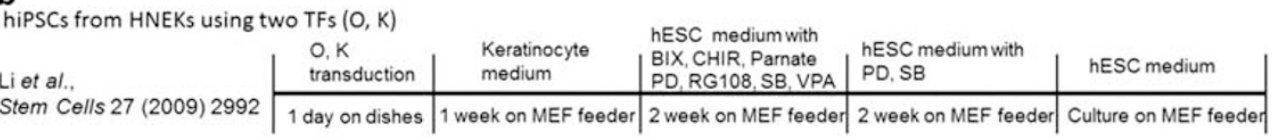

hip

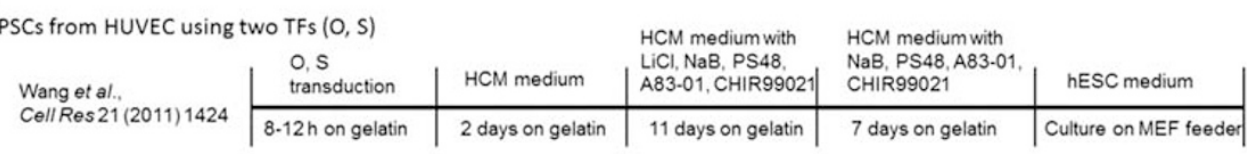

d

hiPSCs from HUVEC using one TF (O)

\begin{tabular}{|c|c|c|c|c|c|}
\hline \multirow{2}{*}{$\begin{array}{l}\text { Zhu et al., Cell1 (2010)651 } \\
\text { Cell Stem Cell7 }\end{array}$} & $\begin{array}{l}\text { Oct } 4, \text { Sox } 2 \\
\text { transduction }\end{array}$ & $\begin{array}{l}\text { HCM medium with } \\
\text { NaB, PS48.,A83-01, } \\
\text { parnate, CHIR }\end{array}$ & $\begin{array}{l}\text { hESC medium with } \\
\text { NaB, PS48, A83-01, } \\
\text { parnate, CHIR }\end{array}$ & $\begin{array}{l}\text { hESC medium with } \\
\text { NaB, PS48, A83.01, } \\
\text { parnate, CHIR, PD }\end{array}$ & hESC medium \\
\hline & $8-12 \mathrm{~h}$ on gelatin & 2 weeks on gelatin & 2 weeks on gelatin & 1-2 weeks on gelatin & \\
\hline
\end{tabular}

e

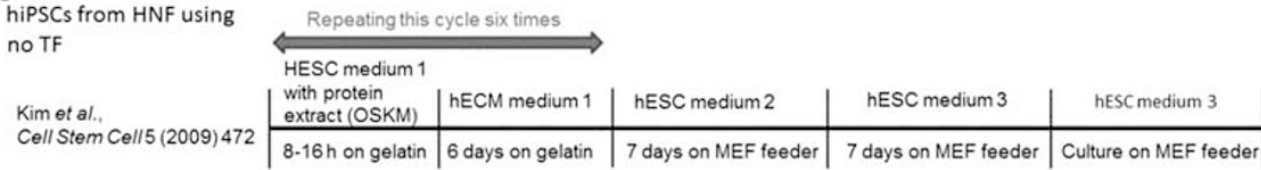

f hiPSCs from hNPCs using

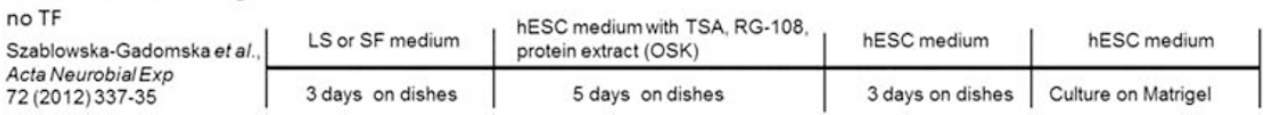

Figure 6 Schematic representation of hiPSC generation from human somatic cells by reducing the number of TFs with and without small molecules. (a) hiPSCs using four TFs (Oct4 [O], Sox2 [S], KIf4 [K], and c-Myc [M]); ${ }^{8}$ (b) hiPSCs from human neonatal epidermal keratinocytes (HNEKs) using two TFs $(\mathrm{O}, \mathrm{K}) ;{ }^{71}$ (c) hiPSCs from human umbilical vein endothelial cells (HUVECs) using two TFs $(\mathrm{O}, \mathrm{S}) ;^{70}$ (d) hiPSCs from HUVECs using one TF (O); ${ }^{43}$ (e) hiPSCs from human newborn fibroblasts (HNFs) using no TFs; ${ }^{18}$ and (f) hiPSCs from human NSCs using no TFs. ${ }^{90}$ HCM medium indicates EndoGRO-VEGF complete medium (CHEMICON). LS and SF medium indicates low-serum and serum-free media, respectively. O, S, K, and M indicate the TFs Oct4, Sox2, KIf4, and c-Myc, respectively.

NSCs endogenously express Sox2, Klf4, and/or c-Myc to some extent, as was discussed in the previous section (Figure 5). Therefore, Kim et al. reprogrammed human fetal NSCs into hiPSCs by the transduction of only Oct4. ${ }^{13}$ Their work suggests that only one TF, OCT4, should be sufficient to reprogram human fetal NSCs into hiPSCs. However, it is very difficult to obtain human fetal NSCs to generate patient-specific hiPSCs, and the efficiency of hiPSC generation is reported to be only $0.006 \%$ in their study. ${ }^{13}$

Zhu et al. developed their four-step protocol to generate hiPSCs from neonatal human epidermal keratinocytes, human umbilical vein endothelial cells (HUVECs), and amniotic-derived cells. ${ }^{43}$ In the case of HUVEC-derived hiPSCs, the following protocol was used. (a) In the first stage, Oct4 was transduced into cells cultured on gelatin-coated dishes for $8-12 \mathrm{~h}$. (b) In the second stage, the cells were cultured in HUVEC medium containing sodium butyrate, PS48, A83-01, tranylcypromine, and CHIR99021 for 2 weeks on the gelatin. (c) In the third stage, the cells were cultured in hESC medium containing sodium butyrate, PS48, A83-01, tranylcypromine, and CHIR99021 for another 2 weeks on the gelatin. (d) In the fourth stage, the cells were cultured in hESC medium containing sodium butyrate, PS48, A83-01, tranylcypromine, CHIR99021, and PD0325901 for an additional 1-2 weeks on the gelatin to complete the full cellular reprogramming (Figure 6d). It was suggested that the single TF, Oct4, combined with a defined small-molecule cocktail is capable of reprogramming several human somatic cell types into hiPSCs that are functionally similar to pluripotent hESCs in terms of morphology, gene and protein expression, and differentiation capacity. ${ }^{43}$ However, the reprogramming efficiency was extremely low $(0.004 \%)$ because hiPSCs rather than miPSCs were generated. 
Table 4 Reprogramming of human somatic cells into hiPSCs by transduction with and without TFs with the aid of small molecules

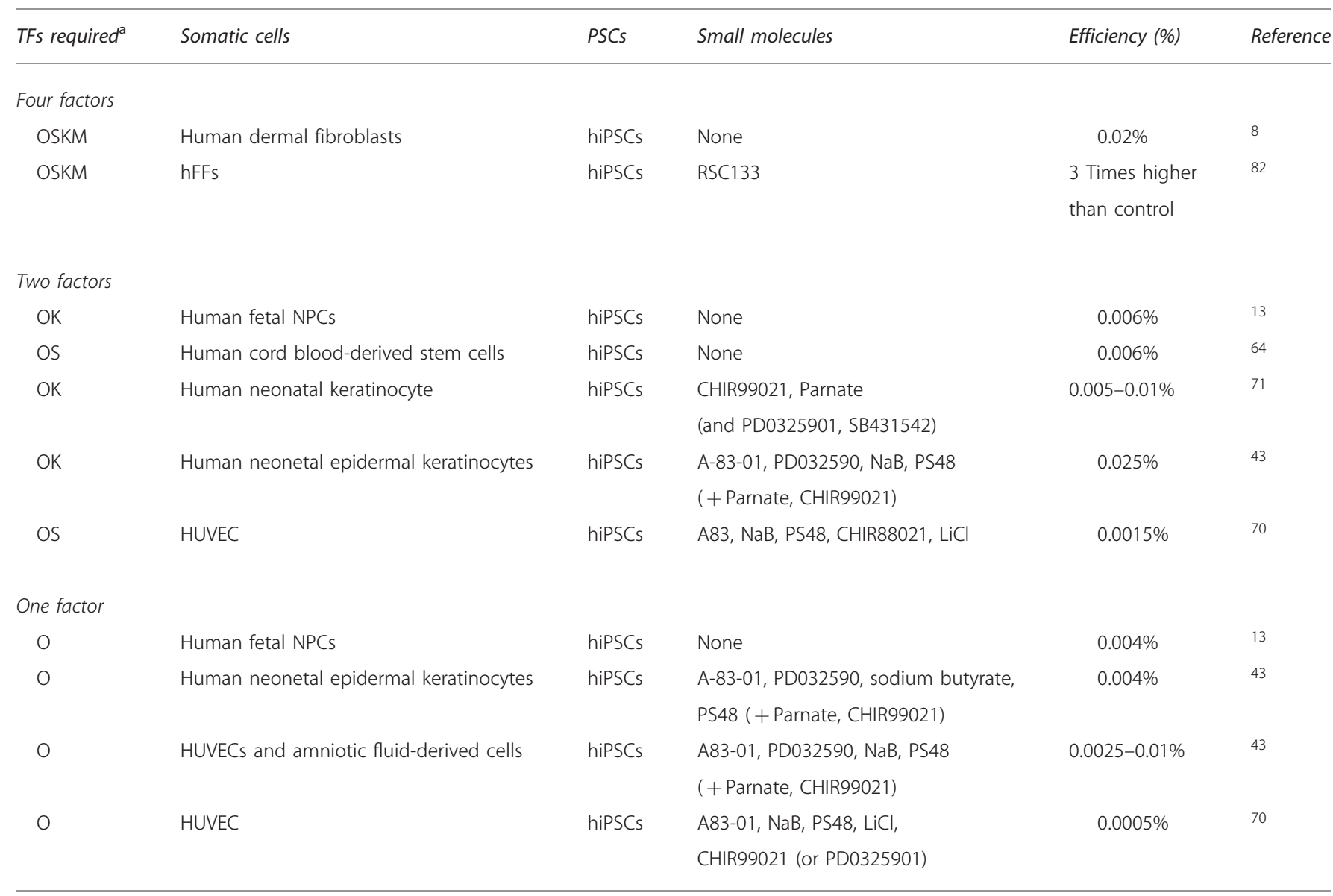

Abbreviations: hFF, human foreskin fibroblast; TF, transcription factor.

${ }^{\mathrm{a}} \mathrm{O}, \mathrm{S}, \mathrm{K}$, and $\mathrm{M}$ indicate Oct4, Sox2, KIf-4, and c-Myc, respectively.

Wang et al. also generated hiPSCs using either one transduced factor (Oct4) or two transduced factors (Oct4 and Sox2) with the aid of small molecules. ${ }^{70}$ They used smallmolecule cocktails similar to those used by Zhu et al. ${ }^{43}$ but also treated the cells with $\mathrm{LiCl}(5 \mathrm{mM})$ from days 3 to 18 , which facilitated miPSC and hiPSC generation (Figure 6c). ${ }^{70}$ hiPSC colonies were picked for expansion on feeder cells after approximately 1 month. The effect of $\mathrm{LiCl}$ on promoting reprogramming was only partially dependent on its major target, GSK-3 $\beta .^{70}$ However, $\mathrm{LiCl}$ is unlike other GSK-3 $\beta$ inhibitors, as it enhances Nanog expression and also promotes its transcriptional activity. $\mathrm{LiCl}$ also works by promoting epigenetic modifications via the downregulation of an H3K4-specific histone demethylase, LSD1. However, the efficiency of hiPSC generation was still extremely low $(0.0015$ and $0.0005 \%$ for two-factor and one-factor transduction, respectively).

If hiPSCs can be generated from patient-specific cells and/ or different human leukocyte antigen (HLA) types of human somatic cells using only chemically defined small molecules with high efficiency (eg, preferentially $>0.1 \%$ ), the door would be opened for the potential use of hiPSCs in clinical applications. Currently, to our knowledge, hiPSC generation solely based on chemically defined small molecules has not yet been reported, although hiPSCs have been generated using cell extracts and/or proteins without the use of TFs. ${ }^{18,58,90}$

\section{CONCLUSIONS AND PERSPECTIVES}

Introduction of small and large molecules can target signaling transduction pathways and can affect DNA replication, cell differentiation, apoptosis, and the reprogramming of the cells into iPSCs. Several specific small molecules can successfully enhance the reprogramming efficiencies of mouse and human somatic cells into iPSCs. Since 2013, miPSCs have been generated via treatment with small molecules without the use of genetic material. ${ }^{17,68}$ However, it is still challenging to generate hiPSCs by treating cells with only small molecules. The generation of human and mouse piPSCs using pluripotent proteins or cell extracts without the 


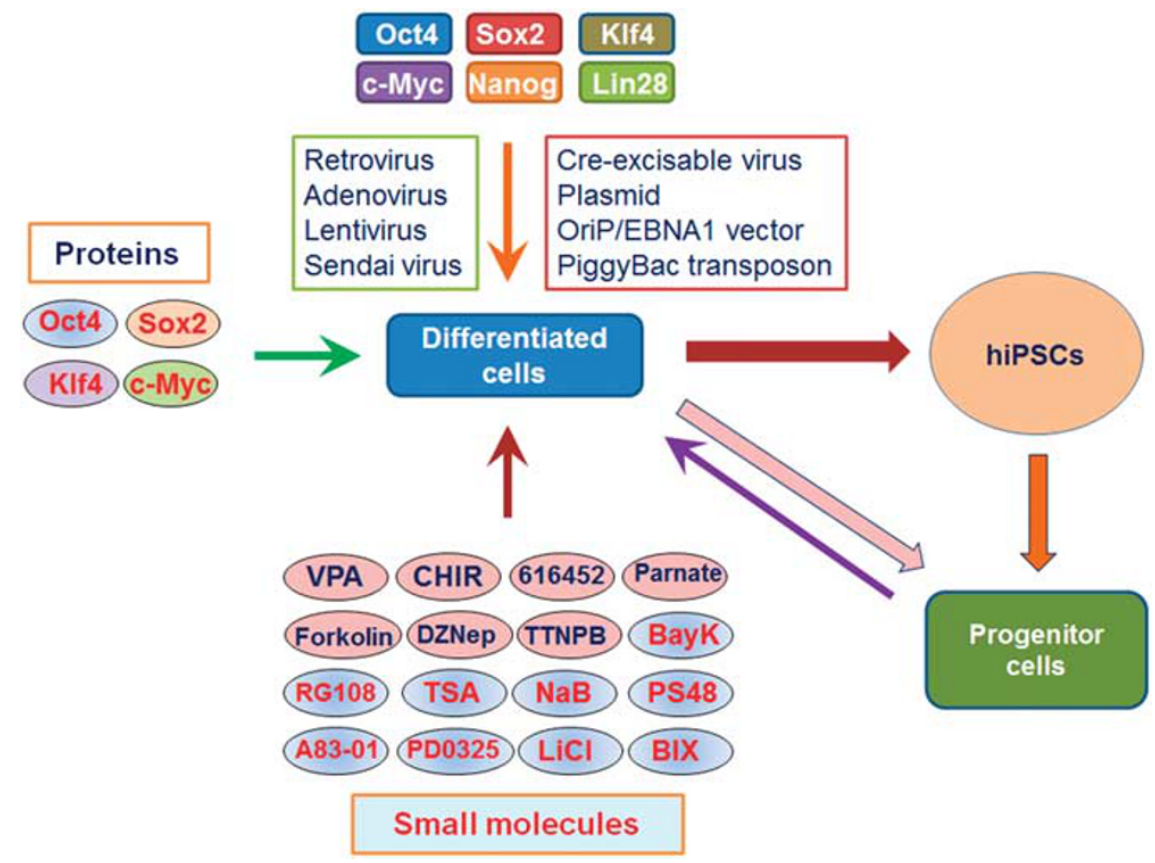

Figure 7 Schematic illustration of somatic cell reprogramming to iPSCs and progenitor or adult stem cells. Somatic cells can be reprogrammed to iPSCs using viral or non-viral introduction of exogenous TFs or protein transfection. Small molecules can either substitute for certain TFs and/or improve reprogramming efficiency by epigenetic modifications or signaling pathway regulation. The abbreviations of the small molecules are shown in Table 2.

use of genetic material has been reported. ${ }^{18,21}$ However, currently, piPSCs are not a popular method for generating iPSCs, although more than 5 years has passed since the first reports of their generation. The hesitancy to adopt the method is likely due to the extremely low generation efficiency and the difficulty of preparing pluripotent proteins tagged with CPP. Figure 7 summarizes the reprogramming methods that have been developed and that may be promising in the future. Currently, target cells, such as dopamine-secreting cells, insulin-secreting $\beta$ cells, and cardiomyocytes, may be prepared from PSCs as follows: (a) somatic cells from blood, fat tissue, or other sources of tissues are isolated; (b) the somatic cells are reprogrammed into iPSCs; and (c) iPSCs are differentiated into the targeted cells. In this case, which includes the use of hESCs and hiPSCs, it is extremely difficult to obtain highly pure populations of the target cells. Furthermore, it is impossible to avoid the potential for tumor generation when these targeted cells are transplanted into humans. ${ }^{91}$ Therefore, we suggest that the direct reprogramming of somatic cells into progenitor (stem) cells, including adult stem cells, such as NSCs, cardiomyocyte progenitor cells, hepatocyte stem cells, hematopoietic stem cells, and mesenchymal stem cells, as an attractive alternative for clinical applications. It will be interesting to develop small molecules to guide human somatic cells into the transdifferentiation of tissue-specific progenitor cells or stem cells. ${ }^{76,92-95}$ In this case, xeno-free cultures are much easier for culturing the progenitor cells compared with PSCs because MEFs are not required for the culturing of progenitor cells and adult stem cells. Although
NSCs are reported to be able to proliferate for more than 20130 passages, ${ }^{96-98}$ mesenchymal stem cells, such as adiposederived stem cells and amniotic fluid stem cells, have limited proliferation capacities (eg, 8-12 passages). Therefore, the establishment of small molecules to extend the proliferation of adult stem cells and progenitor cells should be a priority in regenerative medicine. Because bone marrow stem cells and hematopoietic stem cells are ready to be used in clinical applications, the only obstacle to the use of these adult stem cells in clinical applications is their limited proliferation and their overall shortage, which leads to low numbers of clinical trials. The shortages of progenitor cells and adult stem cells can be addressed by reprogramming somatic cells into progenitor cells and adult stem cells using small molecules, which do not disrupt or interrupt host cell genomes. The development of small molecules to guide human somatic cells into progenitor cells, adult stem cells, and iPSCs will open avenues for the clinical application of these types of progenitor cells and stem cells. ${ }^{65,99,100}$

\section{ACKNOWLEDGMENTS}

This research was partially supported by the Ministry of Science and Technology of Taiwan under Grant numbers 102-2120-M-008-002, and 102-2221-E-008-112-MY2. This work was also supported by the LandSeed Hospital project (NCU-LSH-101-A-001 and NCU-LSH-102-A-003), the National Defense Medical Center Project (102NCU-NDMC-01), and the Cathay General Hospital Project (101CGH-NCU-A2, 102NCU-CGH-02, CGH-MR-10115 and CGH-MR-A10204). A Grant-in-Aid for Scientific Research (number 24560968) from the Ministry of Education, Culture, Sports, Science, and Technology of Japan is also acknowledged. We acknowledge the 
International High Cited Research Group (IHCRG \#14-104), Deanship of Scientific Research, King Saud University, Riyadh, Kingdom of Saudi Arabia. Akon Higuchi thanks King Saud University, Riyadh, Kingdom of Saudi Arabia, for the Visiting Professorship.

\section{DISCLOSURE/CONFLICT OF INTEREST}

The authors declare no conflict of interest.

1. Fujimoto $\mathrm{M}$, Hayashi $\mathrm{H}$, Takagi $\mathrm{Y}$, et al. Transplantation of telencephalic neural progenitors induced from embryonic stem cells into subacute phase of focal cerebral ischemia. Lab Invest 2012;92:522-531.

2. Callahan LA, Xie S, Barker IA, et al. Directed differentiation and neurite extension of mouse embryonic stem cell on aligned poly(lactide) nanofibers functionalized with YIGSR peptide. Biomaterials 2013;34: 9089-9095.

3. Higuchi A, Ling QD, Kumar SS, et al. Design of polymeric materials for culturing human pluripotent stem cells: progress toward feeder-free and xeno-free culturing. Prog Polym Sci 2014;39:1348-1374.

4. Gokhale PJ, Andrews PW. Human embryonic stem cells: 10 years on. Lab Invest 2009;89:259-262.

5. Hankowski $\mathrm{KE}$, Hamazaki $\mathrm{T}$, Umezawa $\mathrm{A}$, et al. Induced pluripotent stem cells as a next-generation biomedical interface. Lab Invest 2011;91:972-977.

6. de Wert G, Mummery C. Human embryonic stem cells: research, ethics and policy. Hum Reprod 2003;18:672-682.

7. Takahashi K, Yamanaka S. Induction of pluripotent stem cells from mouse embryonic and adult fibroblast cultures by defined factors. Cell 2006;126:663-676.

8. Takahashi K, Tanabe K, Ohnuki M, et al. Induction of pluripotent stem cells from adult human fibroblasts by defined factors. Cell 2007;131: 861-872.

9. Okita K, Ichisaka T, Yamanaka S. Generation of germline-competent induced pluripotent stem cells. Nature 2007;448:313-317.

10. Aoi T, Yae K, Nakagawa M, et al. Generation of pluripotent stem cells from adult mouse liver and stomach cells. Science 2008;321:699-702.

11. Yu J, Vodyanik MA, Smuga-Otto K, et al. Induced pluripotent stem cell lines derived from human somatic cells. Science 2007;318:1917-1920.

12. Nakagawa M, Koyanagi $M$, Tanabe $K$, et al. Generation of induced pluripotent stem cells without Myc from mouse and human fibroblasts. Nat Biotechnol 2008;26:101-106.

13. Kim JB, Greber B, Arauzo-Bravo MJ, et al. Direct reprogramming of human neural stem cells by OCT4. Nature 2009;461:649-653.

14. Xie $\mathrm{M}$, Cao N, Ding S. Small molecules for cell reprogramming and heart repair: Progress and perspective. Acs Chem Biol 2014;9:34-44.

15. Li Y, Zhang Q, Yin X, et al. Generation of iPSCs from mouse fibroblasts with a single gene, Oct4, and small molecules. Cell Res 2011;21: 196-204.

16. Kim JB, Sebastiano V, Wu GM, et al. Oct4-induced pluripotency in adult neural stem cells. Cell 2009;136:411-419.

17. Hou $P P, L i Y Q$, Zhang $X$, et al. Pluripotent stem cells induced from mouse somatic cells by small-molecule compounds. Science 2013:341:651-654.

18. Kim D, Kim CH, Moon Jl, et al. Generation of human induced pluripotent stem cells by direct delivery of reprogramming proteins. Cell Stem Cell 2009;4:472-476.

19. Zhou H, Wu S, Joo JY, et al. Generation of induced pluripotent stem cells using recombinant proteins. Cell Stem Cell 2009;4:381-384.

20. Li WL, Ding S. Small molecules that modulate embryonic stem cell fate and somatic cell reprogramming. Trends Pharmacol Sci 2010;31:36-45.

21. Yamanaka S. Strategies and new developments in the generation of patient-specific pluripotent stem cells. Cell Stem Cell 2007;1:39-49.

22. Cohen $D E$, Melton D. Turning straw into gold: directing cell fate for regenerative medicine. Nat Rev Genet 2011;12:243-252.

23. Chun YS, Chaudhari $P$, Jang YY. Applications of patient-specific induced pluripotent stem cells; Focused on disease modeling, drug screening and therapeutic potentials for liver disease. Int J Biol Sc 2010:6:796-805.

24. Nishimura K, Sano M, Ohtaka M, et al. Development of defective and persistent Sendai virus vector: a unique gene delivery/expression system ideal for cell reprogramming. J Biol Chem 2011;286:4760-4771.
25. Stadtfeld M, Nagaya M, Utikal J, et al. Induced pluripotent stem cells generated without viral integration. Science 2008;322:945-949.

26. Zhou WB, Freed CR. Adenoviral gene delivery can reprogram human fibroblasts to induced pluripotent stem cells. Stem Cells 2009;27: 2667-2674.

27. Woltjen K, Michael IP, Mohseni P, et al. piggyBac transposition reprograms fibroblasts to induced pluripotent stem cells. Nature 2009;458:766-770.

28. Okita $\mathrm{K}$, Nakagawa $\mathrm{M}$, Hyenjong $\mathrm{H}$, et al. Generation of mouse induced pluripotent stem cells without viral vectors. Science 2008;322: 949-953.

29. Si-Tayeb K, Noto FK, Sepac A, et al. Generation of human induced pluripotent stem cells by simple transient transfection of plasmid DNA encoding reprogramming factors. BMC. Develop Biol 2010;10:81.

30. Yu J, Hu K, Smuga-Otto K, et al. Human induced pluripotent stem cells free of vector and transgene sequences. Science 2009;324:797-801.

31. Kaji K, Norrby K, Paca A, et al. Virus-free induction of pluripotency and subsequent excision of reprogramming factors. Nature 2009;458: 771-775.

32. MacArthur CC, Fontes A, Ravinder N, et al. Generation of humaninduced pluripotent stem cells by a nonintegrating RNA sendai virus vector in feeder-free or xeno-free conditions. Stem Cells Int 2012; 2012:564612.

33. Chou BK, Mali P, Huang XS, et al. Efficient human iPS cell derivation by a non-integrating plasmid from blood cells with unique epigenetic and gene expression signatures. Cell Res 2011;21:518-529.

34. Cheng L, Hansen NF, Zhao $L$, et al. Low incidence of DNA sequence variation in human induced pluripotent stem cells generated by nonintegrating plasmid expression. Cell Stem Cell 2012;10:337-344.

35. Lin SL, Chang DC, Chang-Lin S, et al. Mir-302 reprograms human skin cancer cells into a pluripotent ES-cell-like state. RNA 2008;14: 2115-2124.

36. Soldner F, Hockemeyer D, Beard C, et al. Parkinson's disease patientderived induced pluripotent stem cells free of viral reprogramming factors. Cell 2009;136:964-977.

37. Warren L, Manos PD, Ahfeldt T, et al. Highly efficient reprogramming to pluripotency and directed differentiation of human cells with synthetic modified mRNA. Cell Stem Cell 2010;7:618-630.

38. Firestone AJ, Chen JK. Controlling destiny through chemistry: Smallmolecule regulators of cell fate. Acs Chem Biol 2010;5:15-34.

39. Wu YL, Pandian GN, Ding YP, et al. Clinical grade iPS cells: Need for versatile small molecules and optimal cell sources. Chem Biol 2013;20:1311-1322.

40. Zhu S, Wei W, Ding S. Chemical strategies for stem cell biology and regenerative medicine. Annu Rev Biomed Eng 2011;13:73-90.

41. Feng $\mathrm{B}, \mathrm{Ng} \mathrm{JH}$, Heng JCD, et al. Molecules that promote or enhance reprogramming of somatic cells to induced pluripotent stem cells. Cell Stem Cell 2009;4:301-312.

42. Huangfu D, Maehr R, Guo W, et al. Induction of pluripotent stem cells by defined factors is greatly improved by small-molecule compounds. Nat Biotechnol 2008:26:795-797.

43. Zhu SY, Li WL, Zhou HY, et al. Reprogramming of human primary somatic cells by OCT4 and chemical compounds. Cell Stem Cell 2010;7:651-655

44. Zhang XZ. Modulation of embryonic stem cell fate and somatic cell reprogramming by small molecules. Reprod Biomed Online 2010;21: 26-36.

45. Anastasia L, Pelissero G, Venerando $B$, et al. Cell reprogramming: expectations and challenges for chemistry in stem cell biology and regenerative medicine. Cell Death Differ 2010;17:1230-1237.

46. Li WL, Jiang K, Ding S. Concise review: A chemical approach to control cell fate and function. Stem Cells 2012;30:61-68.

47. Lu JY, Kong $X Q$, Luo $C$, et al. Application of epigenome-modifying small molecules in induced pluripotent stem cells. Med Res Rev 2013:33:790-822.

48. Lukaszewicz Al, McMillan MK, Kahn M. Small molecules and stem cells. Potency and lineage commitment: The new quest for the fountain of youth. J Med Chem 2010;53:3439-3453.

49. Groß B, Sgodda M, Rasche M, et al. Improved generation of patientspecific induced pluripotent stem cells using a chemically-defined and matrigel-based approach. Curr Mol Med 2013;13:765-776.

50. Wadia JS, Dowdy SF. Protein transduction technology. Curr Opin Biotech 2002;13:52-56. 
51. Michiue $\mathrm{H}$, Tomizawa $\mathrm{K}$, Wei FY, et al. The NH2 terminus of influenza virus hemagglutinin-2 subunit peptides enhances the antitumor potency of polyarginine-mediated p53 protein transduction. J Biol Chem 2005;280:8285-8289.

52. Inoue $M$, Tomizawa $K$, Matsushita $M$, et al. p53 protein transduction therapy: Successful targeting and inhibition of the growth of the bladder cancer cells. Eur Urol 2006;49:161-168.

53. Lafevre-Bernt M, Wu S, Lin X. Recombinant, refolded tetrameric p53 and gonadotropin-releasing hormone-p53 slow proliferation and induce apoptosis in p53-deficient cancer cells. Mol Cancer Ther 2008;7:1420-1429.

54. Ziegler A, Nervi $P$, Durrenberger $M$, et al. The cationic cell-penetrating peptide CPP(TAT) derived from the HIV-1 protein TAT is rapidly transported into living fibroblasts: optical, biophysical, and metabolic evidence. Biochemistry 2005;44:138-148.

55. El-Sayed A, Futaki S, Harashima H. Delivery of macromolecules using arginine-rich cell-penetrating peptides: ways to overcome endosomal entrapment. Aaps J 2009;11:13-22.

56. Jin J, Kwon YW, Paek JS, et al. Analysis of differential proteomes of induced pluripotent stem cells by protein-based reprogramming of fibroblasts. J Proteome Res 2011;10:977-989.

57. Zhu $X Q$, Pan $X H$, Wang $W B$, et al. Transient in vitro epigenetic reprogramming of skin fibroblasts into multipotent cells. Biomaterials 2010;31:2779-2787.

58. Zheng Z, Jian J, Zhang XL, et al. Reprogramming of human fibroblasts into multipotent cells with a single ECM proteoglycan, fibromodulin. Biomaterials 2012;33:5821-5831.

59. Cho HJ, Lee CS, Kwon YW, et al. Induction of pluripotent stem cells from adult somatic cells by protein-based reprogramming without genetic manipulation. Blood 2010;116:386-395.

60. Rajasingh J, Lambers E, Hamada H, et al. Cell-free embryonic stem cell extract-mediated derivation of multipotent stem cells from NIH3T3 fibroblasts for functional and anatomical ischemic tissue repair. Circ. Res. 2008;102:E107-E117.

61. Rhee $\mathrm{YH}$, Ko JY, Chang MY, et al. Protein-based human iPS cells efficiently generate functional dopamine neurons and can treat a rat model of Parkinson disease. J Clinical Invest 2011;121:2326-2335.

62. Vezoli J. Recombinant proteins to induce pluripotent stem cells: Promises for a safer and thriving step toward clinical trials. Movement Disord 2011;26:1409-1409.

63. Shi Y, Desponts C, Do JT, et al. Induction of pluripotent stem cells from mouse embryonic fibroblasts by Oct4 and Klf4 with small-molecule compounds. Cell Stem Cell 2008;3:568-574.

64. Giorgetti A, Montserrat N, Aasen T, et al. Generation of induced pluripotent stem cells from human cord blood using OCT4 and SOX2. Cell Stem Cell 2009;5:353-357.

65. Jung DW, Kim WH, Williams DR. Reprogram or reboot: Small molecule approaches for the production of induced pluripotent stem cells and direct cell reprogramming. Acs Chem Biol 2014;9:80-95.

66. Sterneckert J, Hoing S, Scholer HR. Concise review: Oct4 and more: The reprogramming expressway. Stem Cells 2012;30:15-21.

67. Shi Y, Do JT, Desponts C, et al. A combined chemical and genetic approach for the generation of induced pluripotent stem cells. Cell Stem Cell 2008;2:525-528.

68. Pasha Z, Haider HK, Ashraf M. Efficient non-viral reprogramming of myoblasts to stemness with a single small molecule to generate cardiac progenitor cells. PLoS One 2011;6:e23667.

69. Ichida JK, Blanchard J, Lam K, et al. A small-molecule inhibitor of tgfBeta signaling replaces sox 2 in reprogramming by inducing nanog. Cell Stem Cell 2009;5:491-503.

70. Wang Q, Xu XX, Li J, et al. Lithium, an anti-psychotic drug, greatly enhances the generation of induced pluripotent stem cells. Cell Res 2011;21:1424-1435.

71. Li W, Zhou H, Abujarour $\mathrm{R}$, et al. Generation of human-induced pluripotent stem cells in the absence of exogenous Sox2. Stem Cells 2009;27:2992-3000.

72. Staerk J, Lyssiotis CA, Medeiro LA, et al. Pan-Src family kinase inhibitors replace Sox2 during the direct reprogramming of somatic cells. Angew Chem Int Edit 2011;50:5733-5735.

73. Yuan $X$, Wan HF, Zhao XY, et al. Brief report: Combined chemical treatment enables Oct4-induced reprogramming from mouse embryonic fibroblasts. Stem Cells 2011;29:549-553.

74. Moon JH, Heo JS, Kim JS, et al. Reprogramming fibroblasts into induced pluripotent stem cells with Bmi1. Cell Res 2011;21:1305-1315.
75. Lyssiotis CA, Foreman RK, Staerk J, et al. Reprogramming of murine fibroblasts to induced pluripotent stem cells with chemical complementation of KIf4. Proc Natl Acad Sci USA 2009;106:8912-8917.

76. Allsopp TE, Bunnage ME, Fish PV. Small molecule modulation of stem cells in regenerative medicine: recent applications and future direction. Medchemcomm 2010;1:16-29.

77. Mikkelsen TS, Hanna J, Zhang XL, et al. Dissecting direct reprogramming through integrative genomic analysis. Nature 2008;454:49-55.

78. Lee MG, Wynder C, Schmidt DM, et al. Histone H3 lysine 4 demethylation is a target of nonselective antidepressive medications. Chem Biol 2006;13:563-567.

79. Mali P, Chou BK, Yen J, et al. Butyrate greatly enhances derivation of human induced pluripotent stem cells by promoting epigenetic remodeling and the expression of pluripotency-Associated genes. Stem Cells 2010;28:713-720.

80. Liang GY, Taranova $\mathrm{O}$, Xia $\mathrm{K}$, et al. Butyrate promotes induced pluripotent stem cell generation. J Biol Chem 2010;285:25516-25521.

81. Yoshida $\mathrm{Y}$, Takahashi $\mathrm{K}$, Okita $\mathrm{K}$, et al. Hypoxia enhances the generation of induced pluripotent stem cells. Cell Stem Cell 2009;5:237-241.

82. Lee J, Xia $Y$, Son MY, et al. A novel small molecule facilitates the reprogramming of human somatic cells into a pluripotent state and supports the maintenance of an undifferentiated state of human pluripotent stem cells. Angew Chem Int Edit 2012;51:12509-12513.

83. Chen TT, Shen L, Yu J, et al. Rapamycin and other longevity-promoting compounds enhance the generation of mouse induced pluripotent stem cells. Aging Cell 2011;10:908-911.

84. Li ZH, Rana TM. A kinase inhibitor screen identifies small-molecule enhancers of reprogramming and iPS cell generation. Nat Commun 2012;3:2059.

85. Giorgetti A, Montserrat N, Rodriguez-Piza I, et al. Generation of induced pluripotent stem cells from human cord blood cells with only two factors: Oct4 and Sox2. Nat Protoc 2010;5:811-820.

86. Page RL, Ambady S, Holmes WF, et al. Induction of stem cell gene expression in adult human fibroblasts without transgenes. Cloning Stem Cells 2009;11:417-426.

87. Kim JB, Zaehres H, Wu GM, et al. Pluripotent stem cells induced from adult neural stem cells by reprogramming with two factors. Nature 2008;454:646-650.

88. Silva J, Barrandon O, Nichols J, et al. Promotion of reprogramming to ground state pluripotency by signal inhibition. PLoS Biol 2008;6:e253.

89. Huangfu D, Osafune $K$, Maehr $R$, et al. Induction of pluripotent stem cells from primary human fibroblasts with only Oct4 and Sox2. Nat Biotechnol 2008;26:1269-1275.

90. Szablowska-Gadomska I, Sypecka J, Zayat V, et al. Treatment with small molecules is an important milestone towards the induction of pluripotency in neural stem cells derived from human cord blood. Acta Neurobiol Exp 2012;72:337-350.

91. Higuchi A, Ling QD, Chang Y, et al. Physical cues of biomaterials guide stem cell differentiation fate. Chem Rev 2013;113:3297-3328.

92. Masip $\mathrm{M}$, Veiga $\mathrm{A}$, Belmonte $\mathrm{JCl}$, et al. Reprogramming with defined factors: from induced pluripotency to induced transdifferentiation. Mol Hum Reprod 2010;16:856-868.

93. Efe JA, Ding S. The evolving biology of small molecules: controlling cell fate and identity. Philos T R Soc B 2011;366:2208-2221.

94. Roessler R, Boddeke E, Copray S. Induced pluripotent stem cell technology and direct conversion: New possibilities to study and treat Parkinson's disease. Stem Cell Rev Rep 2013;9:505-513.

95. Masuda S, Wu J, Hishida T, et al. Chemically induced pluripotent stem cells (CiPSCs): a transgene-free approach.. J Mol Cell Biol 2013;5: 354-355.

96. Han DW, Tapia N, Hermann A, et al. Direct reprogramming of fibroblasts into neural stem cells by defined factors. Cell Stem Cell 2012;10:465-472.

97. Lujan $\mathrm{E}$, Chanda $\mathrm{S}$, Ahlenius $\mathrm{H}$, et al. Direct conversion of mouse fibroblasts to self-renewing, tripotent neural precursor cells. Proc Natl Acad Sci USA 2012;109:2527-2532.

98. Thier M, Worsdorfer $\mathrm{P}$, Lakes YB, et al. Direct conversion of fibroblasts into stably expandable neural stem cells. Cell Stem Cell 2012;10:473-479.

99. Tapia N, Han DW, Scholer HR. Restoring stem cell function in aged tissues by direct reprogramming? Cell Stem Cell 2012;10:653-656.

100. Li WL, Jiang K, Wei WG, et al. Chemical approaches to studying stem cell biology. Cell Res 2013;23:81-91. 